\title{
966I 4गIEW
}

\section{$y \exists I S \forall W$}

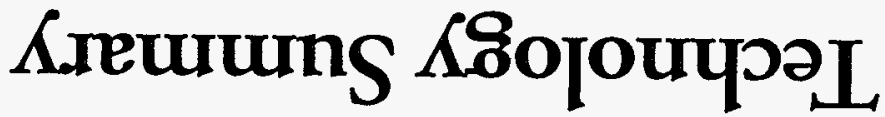

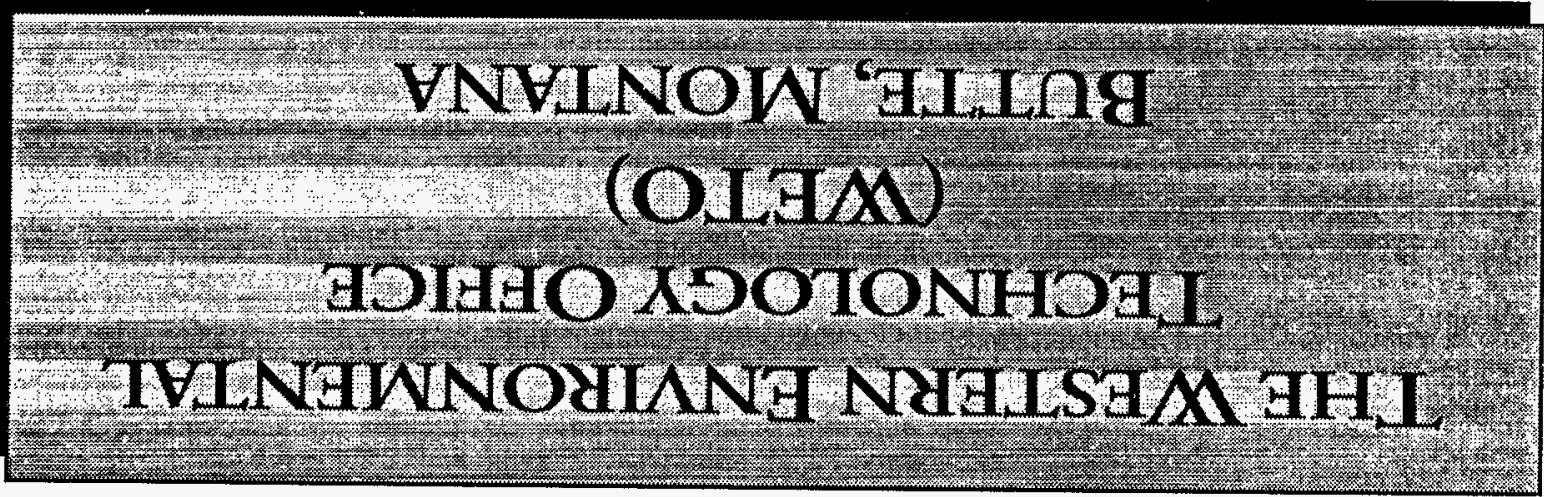

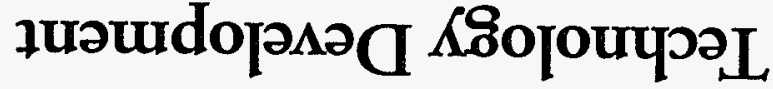

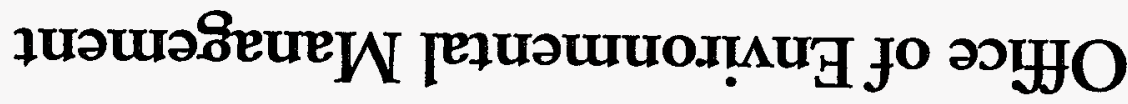

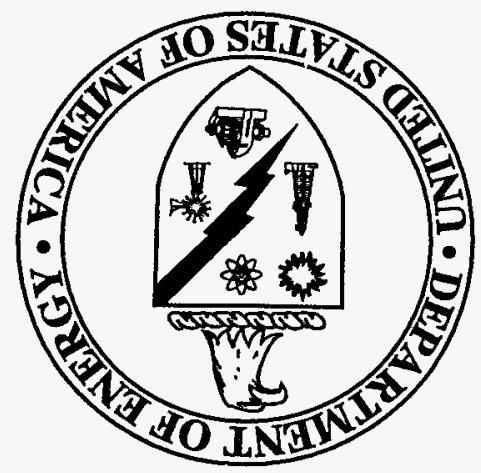




\section{DISCLAIMER}

Portions of this document may be illegible in electronic image products. Images are produced from the best available original document. 


\section{THE WESTERN ENVIRONMENTAL TECHNOLOGY OFFICE (WETO) \\ BUTTE, MONTANA \\ TECHNOLOGY SUMMARY}

\section{TABLE OF CONTENTS}

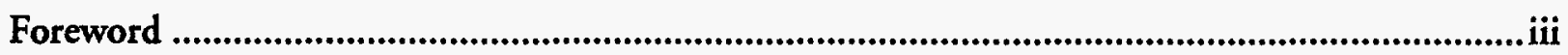

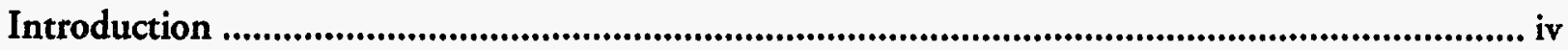

1.0 OFFICE OF SCIENCE AND TECHNOLOGY-SPONSORED PROJECTS ............. 1

\section{Contaminant Plumes Containment and Remediation Focus Area}

1.1 Heavy Metals-Contaminated Soil Project .................................................... 2

1.2 Heavy Metals Separation Technologies ..................................................... 4

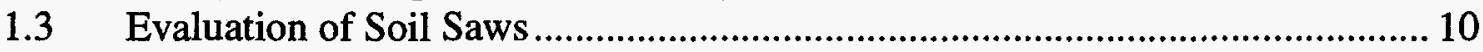

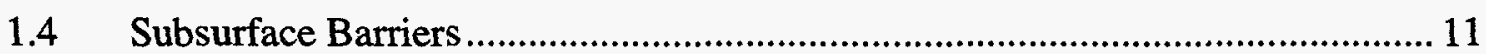

1.5 Development of an Air-Sparging Optimization Model ................................... 12

1.6 Biomass Remediation System '..................................................................... 14

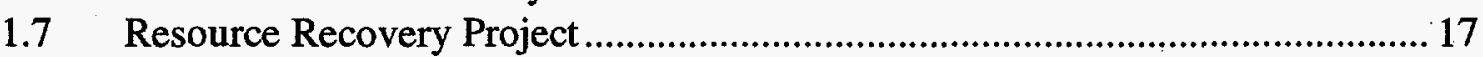

1.8 Resource Recovery Project Technology Demonstrations ................................ 19

1.9 Biologically Formed Subsurface Barrier ................................................... 22

1.10 Investigation of In Situ Mining Technologies for the Treatment of

Contaminated Groundwater .............................................................................. 24

Mixed Waste Characterization, Treatment, and Disposal Focus Area

1.11 WETO Plasma Arc Technology Testing History ............................................. 25

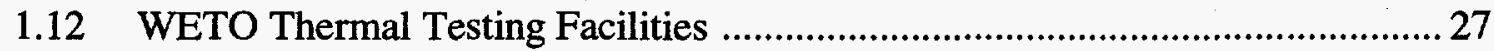

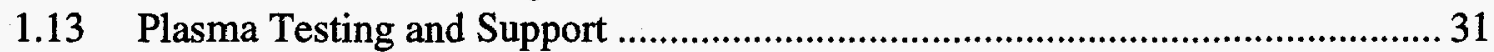

1.14 Controlled Emissions Off-Gas Demonstration .............................................. 33

1.15 Correlation of Plutonium and Cerium Volatility for Bench- and Pilot-Scale Plasma Arc Centrifugal Treatment Systems ................................................... 35

Decontamination and Decommissioning Focus Area

1.16 Radioactive Scrap Metal Recycling ........................................................... 37

Crosscutting Technologies

1.17 RCRA Metals and Air Stream Characterization Project ................................. 39

1.18 Department of Energy/U.S. Air Force Memorandum of Understanding .......... 41

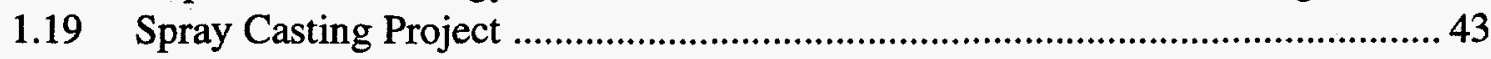


2.1 U.S. Army Construction Engineering Research Laboratory Projects 46

2.2 U.S. Army Ammunition Research Development Engineering Center

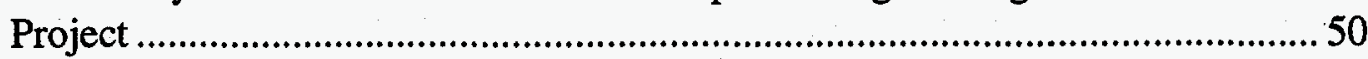

2.3 Mine Waste Technology Program ..................................................................5

2.4 Mine Waste Technology Program Activity III Projects .......................................5 54

2.5 National Aeronautics and Space Administration (NASA)/U.S. Department of Energy (DOE) Magnetohydrodynamic Accelerator Research into Advanced Hypersonics (MARIAH) Project ..........................................................5 56

Figures

1.2a Air-sparged Hydrocyclone Technology ...............................................................................

1.2b Schematic of the Campbell Centrifugal Jig Technology ........................................................

1.2c Centrifugal Gravity Separation Technology ………….........................................................5

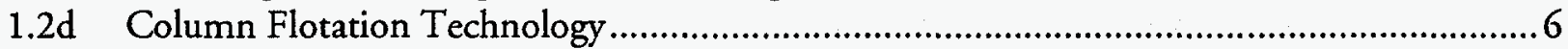

1.2e Automated Mechanical Flow Technology ………..............................................................7

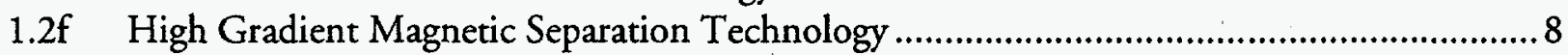

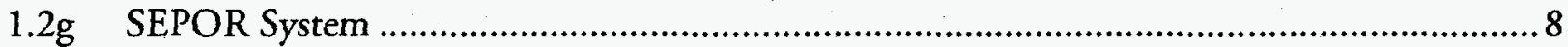

1.6 Functional overview of biomass remediation system evaluation program ...........................14

1.7 The Berkeley Pit, test bed for the Resource Recovery Project …………................................ 17

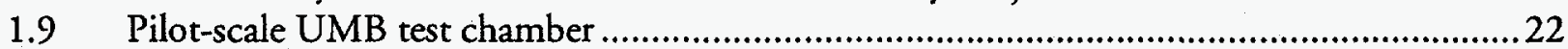

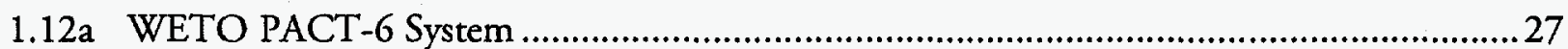

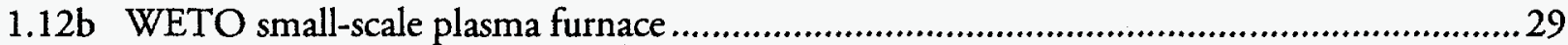

1.16 Process flow diagram for radioactive scrap metal recycling ...................................................... 37

1.18 The industrial processes of the DOE/USAF MOU Program ...........................................4

1.19 Pressure-controlled atomization process. ............................................................................. 43

2.3a Headframe of mine shaft and waste piles at the Lilly/Orphan Boy Mine, site of the SRB Demonstration Project of the MWTP .....................................................................52

2.3b The Mike Horse Mine adit, site of the Clay-Based Grouting Demonstration Project of the MWTP

2.3c The Crystal Mine Complex, site of the Remote Mine Site Demonstration Project of the MWTP 


\title{
FOREWORD
}

This document has been prepared by the U.S. Department of Energy's (DOE's) Office of Environmental Management (EM) Office of Science and Technology (OST) to highlight its research, development, demonstration, testing, and evaluation (RDDT\&E) activities funded through the Western Environmental Technology Office (WETO) in Butte, Montana. Technologies and processes described in this document have the potential to enhance DOE's cleanup and waste management efforts, as well as improve U.S. industry's competitiveness in global environmental markets. The information presented in this document has been assembled from recently produced OST documents that highlight technology development activities within each of the OST program elements and Focus Areas. These Technology Summaries, as well as other OST documents, can be obtained through the EM Central Point of Contact at 1-800-736-3282, and include the following:

Technology Catalogue, April 1995 - DOE/EM-0235

Contaminant Plumes Containment and Remediation Focus Area, June 1995 - DOE/EM-0248

Efficient Separations and Processing Crosscutting Program, June 1995 - DOE/EM-0249

Robotics Technology Crosscutting Program, June 1995 - DOE/EM-0250

Landfill Stabilization Focus Area, June 1995 - DOE/EM-0251

Mixed Waste Characterization, Treatment, and Disposal Focus Area, June 1995 - DOE/EM-0252

Decontamination and Decommissioning Focus Area, June 1995 - DOE/EM-0253

Characterization, Monitoring, and Sensor Technology Crosscutting Program, June 1995 - DOE/EM-0254

Radioactive Tank Waste Remediation Focus Area, June 1995 - DOE/EM-0255

This document presents one in a series for each of DOE's Operations Offices and Energy Technology Centers.

For more information on activities funded through the WETO facility, please contact:

\author{
Melvin W. Shupe, Manager \\ WETO
}

(406) 494-7205 


\section{INTRODUCTION}

\section{DOE's Office of Science and Technology (OST)}

OST manages an aggressive national program for applied research, development, demonstration, testing and evaluation (RDDT\&E). This program develops high-payoff innovative technologies to clean up the inventory of DOE nuclear component manufacturing sites and to manage DOE-generated waste faster, safer, and cheaper than current, or baseline, environmental cleanup technologies.

OST programs are designed to make new, innovative, and more effective technologies available for transfer to potential users through progressive development. Technologies are demonstrated, tested, and evaluated in an effort to produce effective solutions to current problems. The transition of technologies into more advanced stages of development is based upon stringent technological, regulatory, economic, and institutional criteria. New technologies are made available for use in eliminating radioactive, hazardous, and other wastes in compliance with regulatory mandates. The main goal is to protect human health and prevent further contamination.

OST technologies focus on three principal areas: 1) groundwater and soils cleanup, 2) waste retrieval and processing, and 3) pollution prevention. These problems are not unique to DOE, but are also associated with other Federal agency and industry sites. Thus, technical solutions developed within OST programs will benefit DOE and should offer applications to outside markets.

\section{The New ApProach}

Although many positive steps have been taken during the past three decades to remedy the world's environmental problems, the nation's ability to respond to many current and future environmental and economic challenges depends on technological advances produced by a well-organized and productive Federal research and development program.

To ensure that such programs focus on the most pressing environmental restoration and waste management problems at DOE, the Assistant Secretary for the Office of Environmental Management (EM) established a working group in August 1993 to implement a new approach to environmental research and technology development. The goal of DOE's new approach is to conduct a research and technology development program that will overcome the major obstacles in the cleanup of DOE sites. Integral to this new, solutionsoriented approach is an up-front awareness of program needs obtained from customers, users, regulators, and stakeholders. These needs can then be disseminated to the developers of technological solutions.

The key features of the new approach are:

- Establishing five focus areas to address DOE's most pressing problems;

- Teaming with the customers in EM to identify, develop, and implement needed technologies;

- Focusing technology development activities on major environmental management problems;

- Coordinating management of scientific and development activities in support of EM;

- Focusing resources in national laboratories more effectively;

- Involving industry in developing and implementing solutions, including technology transfer into DOE and from DOE to the private sector; 
- Coordinating basic research by involving academia and other research organizations to stimulate technological breakthroughs; and

- Enhancing involvement of regulators and stakeholders in implementation of technology development.

DOE has established a framework and strategy for coordinating efforts among DOE organizations, Management and Operations $(\mathrm{M} \& \mathrm{O})$ contractors, the national laboratories, other Federal agencies, the scientific community, industry, academia, and the affected public. Full implementation of the new approach is planned for the FY95/96 timeframe. The new strategy will build upon existing programs and will seek continual improvement of all EM operations and processes.

\section{BENEFITS}

A keystone for implementation of the new approach is to encourage development of technologies that are better, faster, safer, and more cost-effective than those currently available. More importantly, the new approach has been adopted to foster implementation of new and innovative environmental technologies, facilitating the national commitment to long-term environmental, energy, and economic goals.

An important benefit to the new approach is the creation of investment returns for developing new technologies-technology dividends. These technology dividends result from partnerships and leveraging within government and between governments and the private sector. The partnerships can consist of technology developers, technology users, problems holders, and problem solvers.

EM technology dividends will include:

- Employment opportunities with new businesses and existing businesses;

- Cleanup of sites posing the greatest threats to human health, safety, and the environment;

- Materials reused and recycled, instead of thrown away or freshly contaminated;

- Pollution prevention;

- More effective and efficient industrial processes, leading to greater U.S. competitiveness globally; and

- Technology transfer to industry and other nations.

By implementing the new approach for the unique environmental problems associated with DOE sites, scientists and engineers stand at the threshold of opportunity to develop new technologies. This work will enhance quality of life through a cleaner environment and improved global competitiveness and will ensure job opportunities for American workers.

\section{WETO's CONTRIBUTIONS}

In April 1994, DOE announced its plan to transfer the Component Development and Integration Facility (CDIF) from Fossil Energy to Environmental Management. Along with this transfer, the CDIF was renamed the Western Environmental Technology Office (WETO). WETO is a multi-purpose engineering test facility located in Butte, Montana, and is managed by MSE, Inc. Established in 1974, WETO employs more than 200 highly skilled scientists, engineers, and technicians. WETO originally focused its work on coal-fired electric power generation projects and magnetohydrodynamic (MHD) component testing to find ways to burn coal more cleanly and efficiently. Since its reassignment, WETO seeks to contribute to environmental research by emphasizing projects to develop heavy metals removal and recovery processes, thermal vitrification systems, and waste minimization/pollution prevention technologies. 
At the Butte facility, projects are sponsored by multiple Federal agencies. DOE has teamed with the U.S. Environmental Protection Agency (EPA), the U.S. Department of Defense (DoD), and the U.S. Department of Interior (DOI) to develop and demonstrate innovative and cost-effective waste treatment technologies. This multi-agency environment fosters cooperative research and data sharing, resulting in rapid transfer of new technologies to confront some of the nation's most urgent and pressing environmental cleanup problems.

WETO's environmental technology research and testing activities focus on the recovery of useable resources from waste. In one of WETO's areas of focus, groundwater contamination, water from the Berkeley Pit, located near the WETO site, is being used in demonstrations directed toward the recovery of potable water and metal from the heavy metal-bearing water. The Berkeley Pit is part of an inactive copper mine near Butte that was once part of the nation's largest open-pit mining operation. The Pit contains approximately 25 billion gallons of Berkeley Pit groundwater and surface water containing many dissolved minerals. As part of DOE/OST's Resource Recovery Project (RRP), technologies are being demonstrated to not only clean the contaminated water but to recover metal values such as copper, zinc, and iron with an estimated gross value of more than $\$ 100$ million. When recovered, the Berkeley Pit waters could benefit the entire Butte valley with new water resources for fisheries, irrigation, municipal, and industrial use.

Renaming the Butte facility WETO reflects the emphasis on environmental technology development and commercialization activities, which will focus on mine cleanup, waste treatment, resource recovery, and water resource management. WETO will serve as a national resource for the development of new and innovative environmental technologies. 


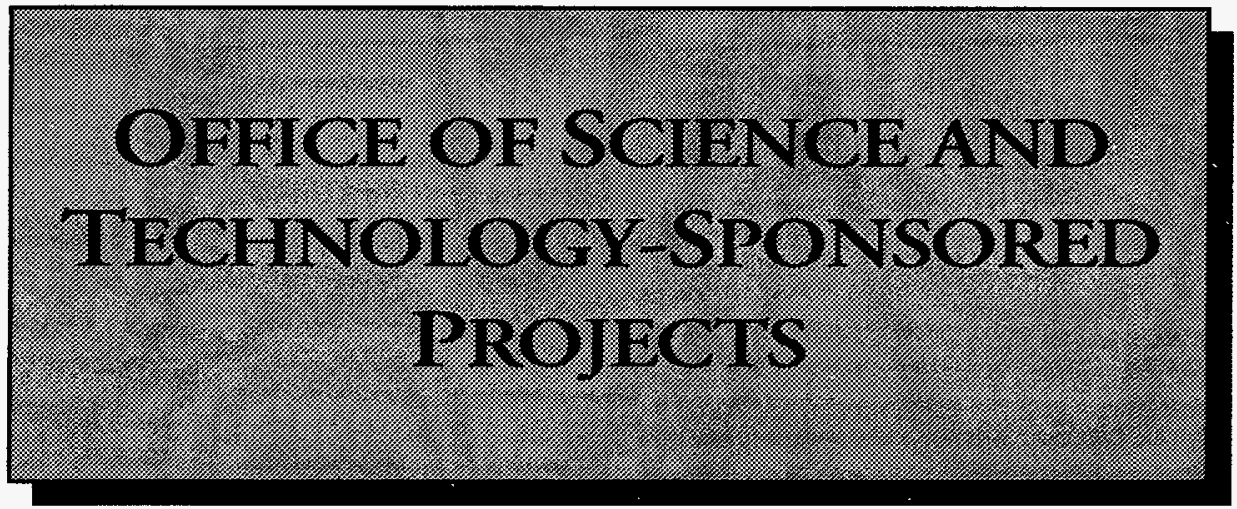

Section 1.0 


\subsection{HeAVY METALS-CONTAMINATEd SOIL PROJECT}

\section{TASK DESCRIPTION}

The primary objective of this project is to conduct treatability studies on soils from the Fernald Site, Idaho National Engineering Laboratory (INEL), Hanford Site, Los Alamos National Laboratory (LANL), and any other U.S. Department of Energy (DOE) site wishing to participate, for the following purposes:

- To determine the decontamination efficiencies of various processes using heavy metal-contaminated soils from DOE sites.

- To provide sufficient data concerning physical and chemical characteristics of the contaminated soils from the participating DOE sites to permit treatability screening of processes for specific soil. These data include soil particle size distribution and its radionuclide distribution as a function of particle size and physical and chemical characteristics.

- To minimize uncertainties in performance efficiency and cost related to decontamination of soils.

Successful decontamination of the soils is defined as a minimum 80 percent reduction in the volume of soil requiring disposal or further treatment.

\section{Technology NeEdS}

There is a large volume of contaminated soil requiring treatment and disposal throughout the DOE Complex. An estimated 20-25 million cubic feet of contaminated soil exists at the Nevada Test Site (NTS) and the adjacent Tonopah Test Range (TTR), and one area at INEL contains 12 million cubic feet of contaminated soil. Other sites that have contaminated soil volumes of this order of magnitude or larger, which must be excavated and disposed of, include Operable Unit 2 at the Rocky Flats Plant, Operable Unit 5 at the Fernald Environmental Management Project (FEMP), LANL, and the DOE Richland Operations Office's Hanford, Washington sites.
DOE has identified a need to develop, test, and demonstrate technologies for the remediation of soils contaminated by various metals. These technologies include soil and vegetation removal, reduction of the volume of contaminated soil (the focus of this project), and ultimate disposal of the contaminated fraction. The costs of disposing of large volumes of contaminated soil in Land Disposal Facilities (LDFs) are relatively high. At the NTS, the current disposal fee for bulk wastes is $\$ 10$ per cubic foot, excluding excavation, handling, and transportation expenses. Therefore, the theoretical minimum cost for disposing of contaminated NTS soil would be on the order of $\$ 200$ million. Excavation using conventional methods produces waste volumes several times larger than the in situ contaminated volume. Estimates based upon the use of conventional excavation technologies indicate that the total remediation cost could be as much as ten times larger, thus increasing NTS costs alone to as much as $\$ 2$ billion.

Technologies developed in this project have the potential to significantly reduce these costs by reducing the contaminated fraction to a maximum of 20 percent of the original volume.

\section{ACCOMPLISHMENTS}

- Completed testing of seven off-the-shelf technologies with surrogate doped soils.

- Designed and built, at the University of Nevada in Reno, a laboratory capable of handling these contaminated soils while ensuring the health and safety of the workers, public, and environment.

- Enlisted the analytical expertise of the U.S. Environmental Protection Agency (EPA) in Montgomery, Alabama, to ensure testing accuracy and to provide the researcher with quality data from which to make determinations.

- Completed testing of six off-the-shelf technologies with contaminated soils from Fernald, Mound, INEL, and LANL. 


\section{COLlaboration/TECHNOLOGY Transfer}

This project is being executed for DOE by the University of Nevada at Reno (UNR) through a subcontract from MSE, Inc. MSE has also procured a Campbell Centrifugal Jig from Trans Mar, Inc., of Spokane, Washington, and an Air-sparged Hydrocyclone from Advanced Processing Technologies, Inc., of Salt Lake City, Utah, for testing at the UNR facility. The United States Naval Academy (USNA) in Annapolis, Maryland, will supply the project with an air-classification unit obtained from the SEPOR system. High-Gradient Magnetic Separation technology will be tested and evaluated at and by personnel from LANL. In addition, UNR has three technologies that will also be tested: a Knelson Concentrator, a Denver Cell, and a Column Flotation technology. All of these technologies are described later in this report.

The data gathered from this project will be supplied to all participating DOE sites, as well as any other site that might be interested in this type of treatment. All information will also be transferred to EM's Office of Environmental Restoration (EM40) for evaluation and potential incorporation into restoration activities. All test results will be made available to the public, the UNR library system, and anyone involved in the restoration of contaminated sites. Discussions are also being held with personnel from Australia and persons in Montana that are experiencing heavy metals contamination at a mine site.

\section{For further information, please contact:}

S. P. (John) Mathur

Program Manager

U.S. Department of Energy

(301) 903-7922

James Wright

Plume Focus Area Manager

U.S. Department of Energy

Savannah River Operations Office

(803) $725-5608$

\section{Creighton Barry}

Program Manager

MSE

(406) 494-7268 


\section{CONTAMinaNt Plumes CONTAINMENT AND REMEDIATION FOCUS AREA}

\subsection{HEAVY METALS SEPARATION TECHNOLOGIES}

\section{The Air-SParged Hydrocyclone}

The Air-Sparged Hydrocyclone (ASH) flotation is a new particle separation technology under development at the University of Utah and Advanced Processing Technologies, Inc. This technology combines froth flotation principles with the flow characteristics of a hydrocyclone, such that the ASH system can perform flotation separations in less than a second. This feature provides the ASH with a high processing capacity, 100-600 times greater than the capacity of conventional flotation or columns.

The ASH consists of two concentric right-vertical tubes, a conventional cyclone header at the top, and a froth pedestal at the bottom. See Figure 1.2a. The inner tube has a porous wall (plastic, ceramic, or stainless steel) through which air is injected. The outer non-porous tube simply serves as an air jacket to provide for even distribution of air through the porous inner tube. The slurry is fed tangentially through the conventional cyclone header to develop a swirl flow of a certain thickness in the radial direction (called the swirl layer thickness) adjacent to the porous wall, leaving an empty air core cen-

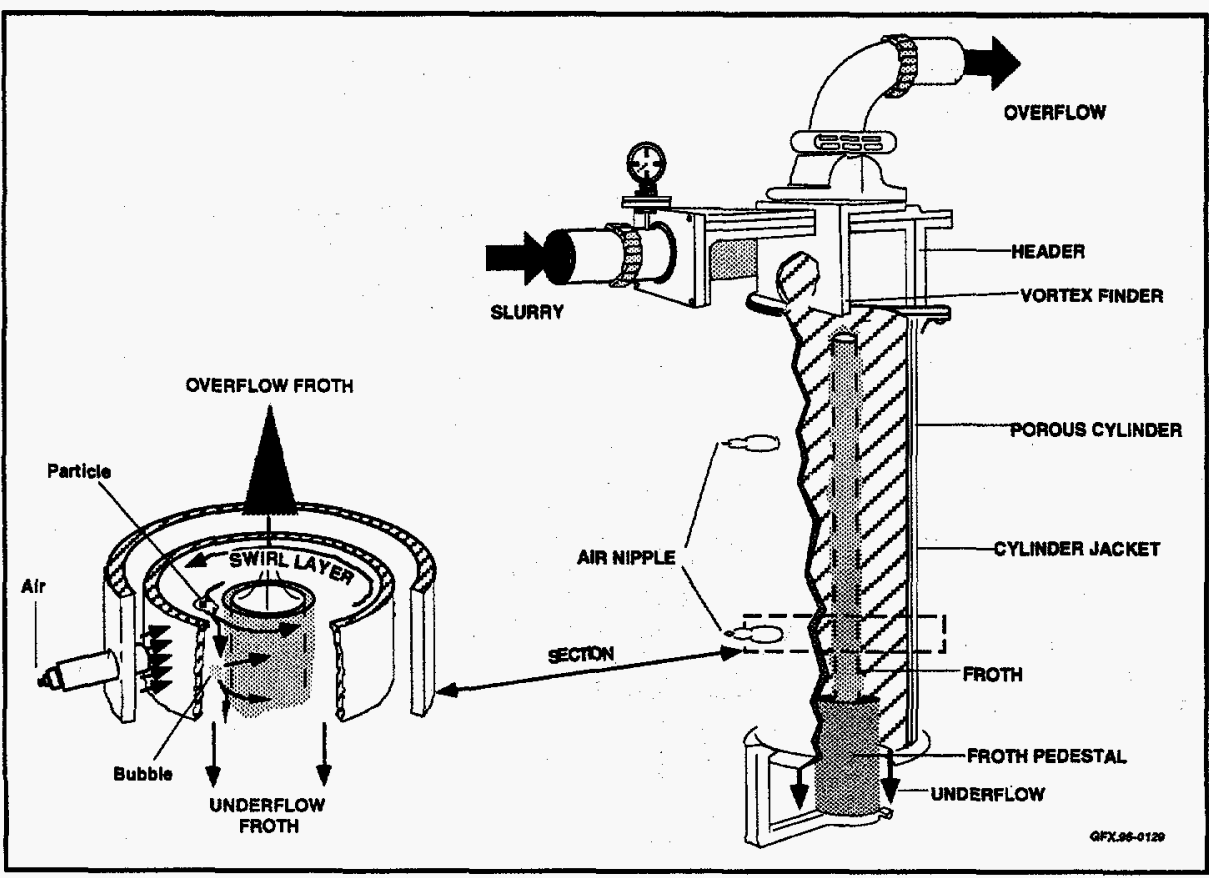

Figure 1.2a. Air-sparged Hydrocyclone Technology. tered on the axis of the ASH. This swirl flow shears the injected air to produce a high concentration of small bubbles. Hydrophobic particles in the slurry collide with these bubbles, and after attachment, lose some of their tangential velocity and centrifugal momentum, and are transported radially into a froth phase that forms at the surface of the air core on the cyclone axis. The froth phase is stabilized and constrained by a froth pedestal at the underflow and thus moves towards the vortex finder of the cyclone header and is discharged as an underflow product through the annular opening between the inner porous wall and the froth pedestal.

\section{The Campbell Centrifugal Jig}

The Campbell Centrifugal Jig (CCJ) is a patented new technology developed by TransMar, Inc., of Spokane, Washington, to separate fine, heavy mineral particles from gangue material (i.e., waste). The CCJ is a combination of two widely used methods of dense particle separation: jigging and centrifuging. The $\mathrm{CCJ}$ combines the effectiveness of continuous flow and pulsating bed of the standard mineral jig with the high " $g$ " forces of the centrifuge. The manner in which this is accomplished is shown in Figure $1.2 \mathrm{~b}$, a schematic showing major elements and flow patterns in the CCJ. The slurry material enters the CCJ through the hollow shaft and is thrown radially outward by the vanes on the diffuser plate to impact on the batter plate, which distributes it over the rotating screen. Pulse blocks rotate with the hutch and screen, and each time they align with one of the inlet ports, the pulse blocks 


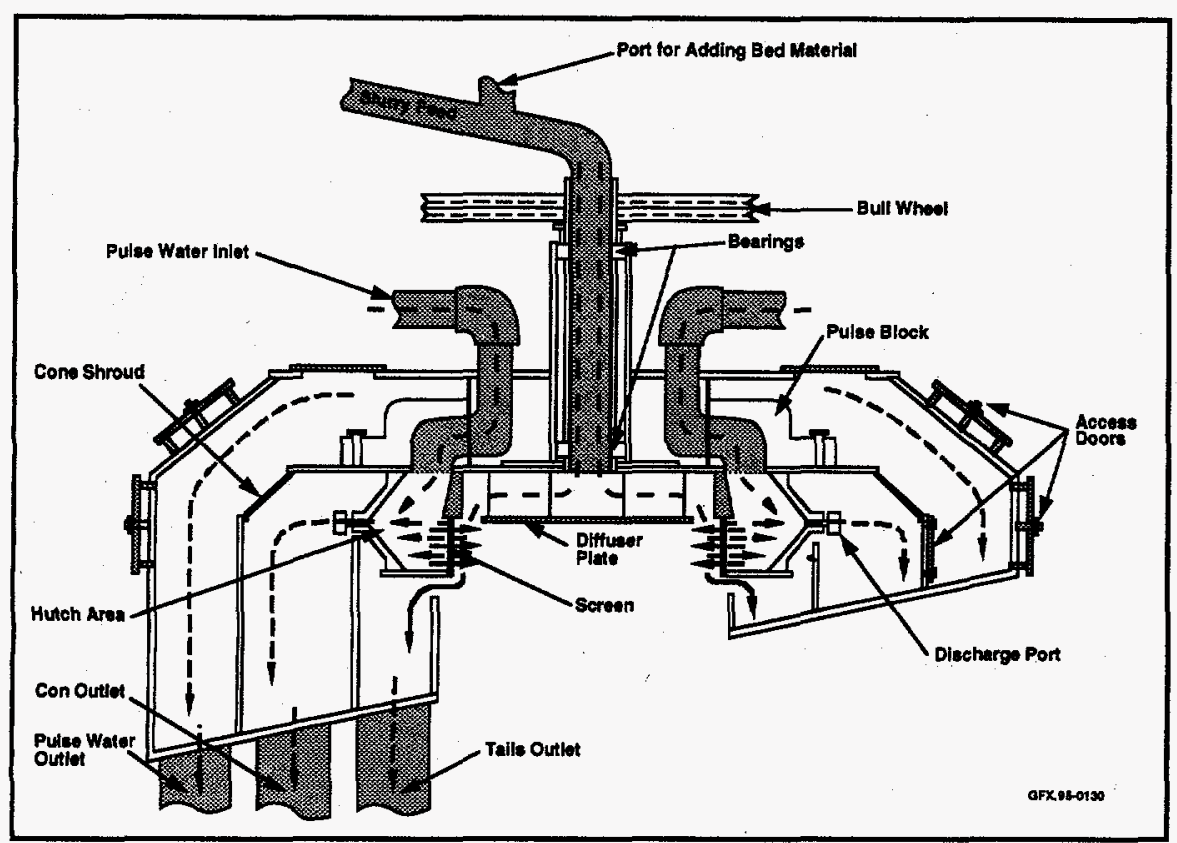

Figure 1.2b. Schematic of the Campbell Centrifugal Jig Technology.

\section{Centrifugal}

GraVtTy

\section{CONCENTRATOR}

The Centrifugal Gravity Concentrator utilizes the principle of hindered settling combined with centrifugal action. See Figure $1.2 \mathrm{c}$. This is made possible with a proprietary mechanism of a water-jacketed perforated cone fed through a hollow shaft-hydraulic device. Gravity concentration devices, like the Centrifugal Gravity Concentrator, depend upon differences in particle size, particle specific gravity, or both (i.e., particle mass) for their effectiveness.

provide a high pressure-intensity water pulse to the outside of the screen, keeping the material fluidized. Heavy particles migrate through the bed and screen and enter the hutch to be recovered through the discharge ports as concentrate. Lighter particles are flushed downward across the jig bed and become tailings.

The Heavy Metals Contaminated Soil Project Phase 1 testing indicated that the $\mathrm{CCJ}$ can reliably remove from 70 to more than 90 percent of the heavy metal surrogate from gangue material. In addition, it can reduce the contaminated volume by factors from close to 100 to over 600 in a single pass through the system; standard gravity separation uses several jigs in a series. It was also demonstrated that the CCJ can successfully operate on very small quantities of feed $(1,500$ to 2,000 pounds) and for short durations (30 minutes or less).
The UNR unit is a centrifugal bowl concentrator with a water jacket around the bowl, essentially a modified centrifuge. Feed slurry enters the rotating ribbed bowl where heavier particles are trapped

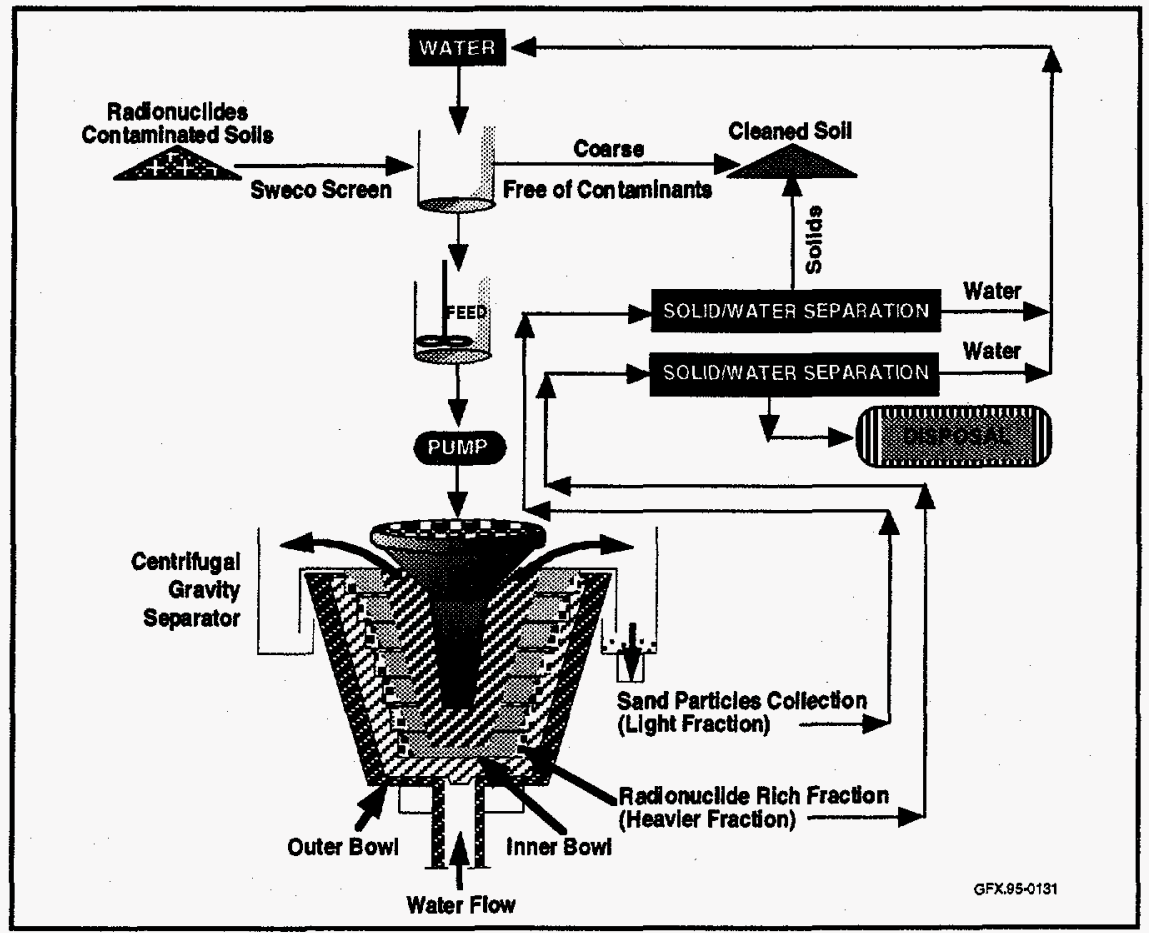

Figure 1.2c. Centrifugal Gravity Separation Technology. 
between the ribs. Compaction of the material between the ribs is prevented by injecting water through holes in the bowl. The water fluidizes the bed and allows heavier particles to continuously displace lighter particles. The water addition is the key to the performance of the Centrifugal Gravity Concentrator. The degree of fluidization controls the effectiveness of separation.

The Centrifugal Gravity Concentrator used in these experiments is a 3-inch stainless steel laboratory model. A motorized force of $60 \mathrm{~g}$ is exerted on the medium. The concentrator handles either coarse or fine feed at 25 percent solids. The model's dimensions are 24 inches in length, 16 inches in width, and 20 inches in height.

\section{Tall Column Flotation}

The effectiveness of mechanical flotation devices decreases in ultra-fine particle size largely because of the large bubble size (as large as $1 \mathrm{~mm}$ ) and turbulent conditions present in the cell. The column flotation technology has been very popular and effective recently in the flotation of ultra-fine particles. Considering the fact that a large fraction of heavy metals is present in 38 micron size soil and its concentration is in the parts per billion (ppb) range, it is conceivable that a combination of conditions such as fine bubble size (30-60 microns), quiescent conditions, and froth drainage mechanism prevalent in the column will result in selective separation of discrete ultra-fine heavy metals from contaminated soil.

The column flotation is a tall device, having at least a length-to-diameter ratio of 10:1. See Figure 1.2d. The reagentized slurry is fed at the upper portion of the column and travels downward.
The hydrophobic particles attach to the rising stream of fine bubbles generated at the bottom of the column. The swarm of air bubble-laden particles are further washed at the top of the column to minimize the entrainment of unwanted material (in this case, clean soil). The contaminate-enriched soil fraction overflows at the top of the column, and hydrophilic clean soil unattached to bubbles is collected at the bottom.

The UNR column is made of plexiglass in four sections, measuring 2 inches in diameter and 10 feet tall. An external bubble generator system is attached at the bottom, which consists of an in-line mixer and a variable speed centrifugal pump. The level control system consists of overflow tubing, a sand-gate valve, and two flow meters (one for wash water and the other for air addition). The automatic level control system is made up of a pressure transducer, controller, and tailings discharge pump.

\section{Automated Mechanical Flotation (Denver Unit)}

Flotation is a physico-chemical process in which one mineral constituent can selectively be separated from another on the basis of surface properties. This is achieved by controlled additions of chemical reagents at a predetermined $\mathrm{pH}$, thereby selectively

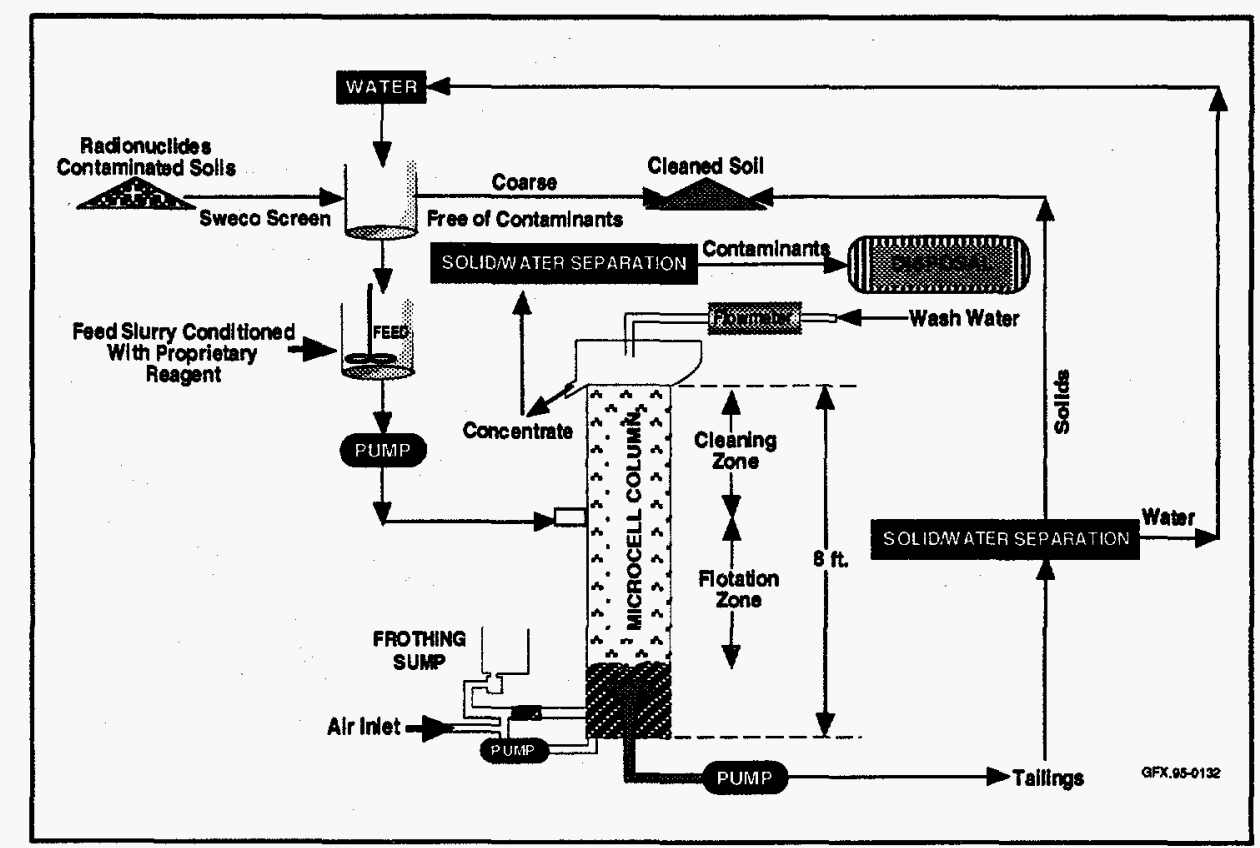

Figure 1.2d. Column Flotation Technology. 
altering the surface characteristics of heavy metalenriched particulates. This treatment renders contaminated soil particles hydrophobic (waterrepellent). Phase separation is then followed by passing air through reagentized slurry. Air bubbles selectively artach to the contaminate-enriched soil particles and are levitated to the surface in the form of froth. The separation of contaminated soil particles renders the remaining soil clean.

The Automated Mechanical Cell, developed by UNR, is a modification of the Denver D-12 laboratory machine that incorporates a 120 VAC adjustable automated froth removal system and a controller to maintain constant pulp-froth interface. See Figure $1.2 \mathrm{e}$. The modification to the Denver unit is in the mounting of the main shaft. The unit has been outfitted with a 90-degree pivoting elbow with a keyed shaft allowing height adjustment and rotation of the unit into operating position. The unit has an adjustable speed motor with a two-blade froth-removing paddle. Critical operational adjustments are made by 1) moving the motor housing laterally on the shaft to regulate clearance in the paddle-dam relationship without the need for any locking mechanism, and 2) moving the vertical collar pivot up or down to set the paddle depth into the froth. The froth collection system consists of a tapered bottom and inclined trough to collect heavy metals. The pulp-froth interface level control is achieved by sensing the vertical position of a float in a sight glass by a proximity switch. The switch is connected to solenoid valves and flow regulators.

\section{High Gradient Magnetic SEPARATION}

Los Alamos National Laboratory, in conjunction with its industrial partner Lockheed Environmental Systems and Technology Co., is exploring a promising new technique that could be used to remove contaminants from soils. The technique, high gradient magnetic separation (HGMS), takes advantage of the fact that all actinide compounds are slightly magnetic. Much of the contaminated soil contains slightly magnetic particles that are attracted by very strong magnetic fields and can thus be separated from the mostly nonmagnetic soil. The availability of reliable superconducting magnets, which create very strong magnetic fields, makes HGMS an attractive method for extracting actinide contaminants. Preliminary experiments with magnetic surrogates and modeling of the process have yielded encouraging results. Contaminated soil samples from DOE sites are now being tested, and the partners are working to develop the process for full-scale site remediation.

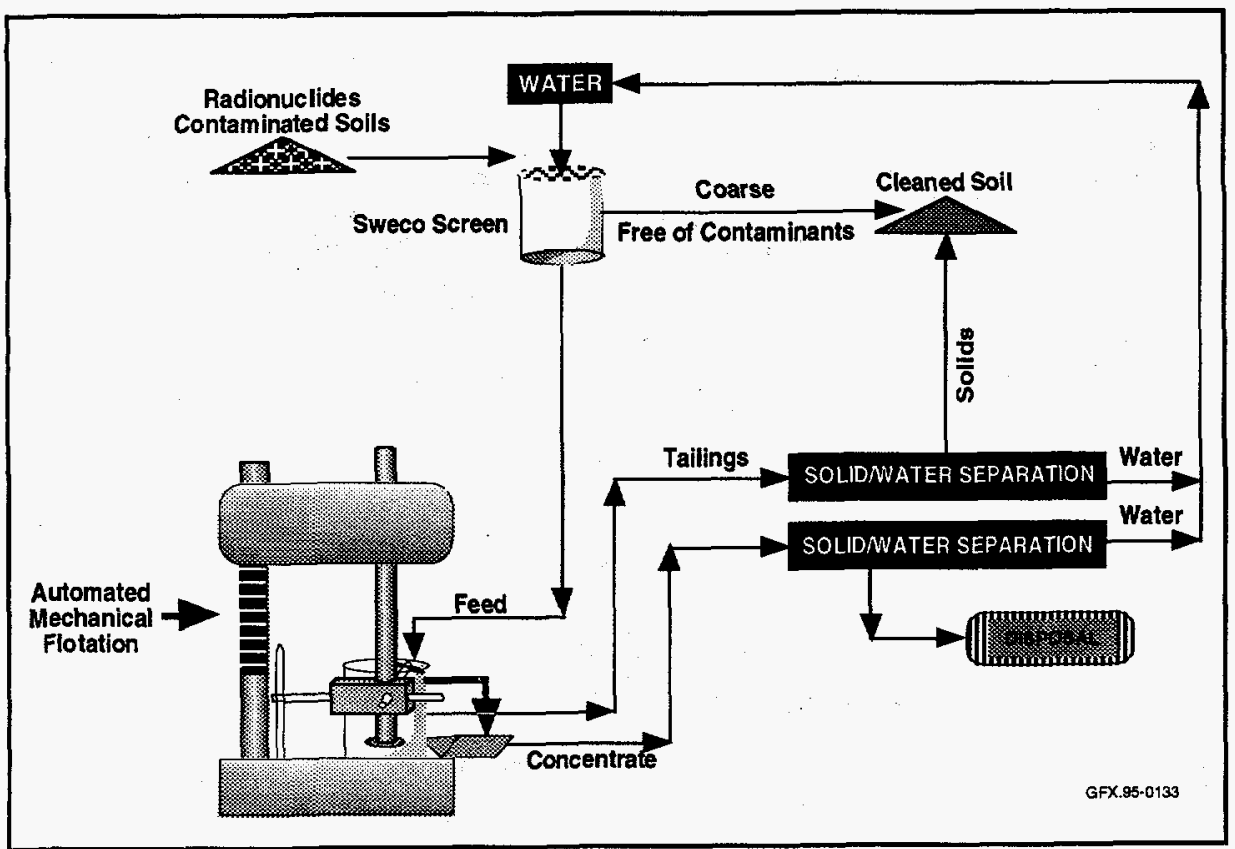

Figure 1.2e. Automated Mechanical Flow Technology.
To begin the HGMS process, a slurry is made by mixing contaminated soil with water. This slurry then flows through a chamber filled with a matrix that can be magnetized, such as steel wool. See Figure 1.2f. A superconducting magnet surrounding the chamber produces a magnetic field strong enough to cause the magnetic particles, including the actinides, to adhere to the matrix. After the batch of slurry has passed through the 


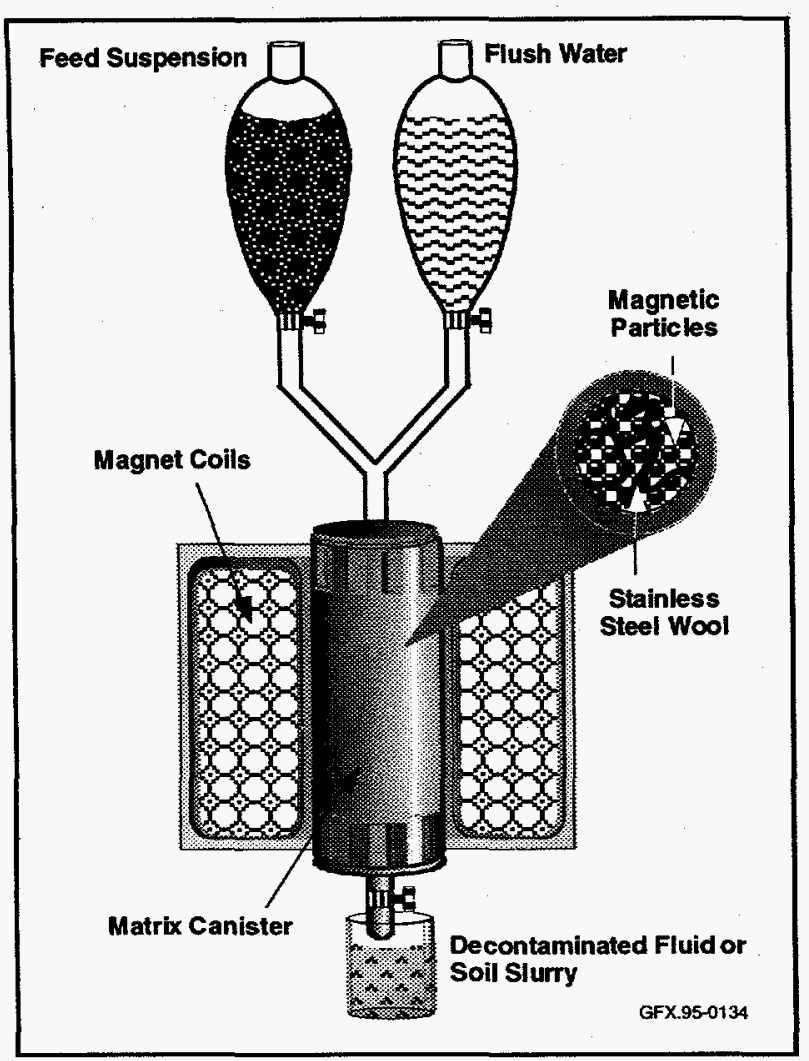

Figure 1.2f. High Gradient Magnetic Separation Technology.

chamber, the magnetic field is removed and water flows through the matrix to flush out the contaminated particles. The residue is then concentrated and packaged for proper storage or disposal, the waste and matrix are recycled, and the soil from the slurry is returned to the environment, if it is sufficiently decontaminated.

\section{THE SEPOR SYSTEM}

The USNA SEPOR system is a commercially available, bench-scale air separation technology being evaluated by the USNA to remove heavy metals from soils.

The system produces two effluent streams, one containing predominately smaller particles and referred to as the fine discharge, and the other containing predominately larger particles, referred to as the coarse discharge. The goal of the evaluation is to concentrate most of the heavy metal in one of the effluent streams so as to reduce the volume of contaminated soil requiring site removal.

The USNA SEPOR system uses a centrifugal force effect to achieve separation. A schematic of this system is shown in Figure 1.2g. The contaminated soil is fed into this system through a feed pipe, where it then falls into a separating chamber. Separation is achieved through action of a centrifugal fan, which aerodynamically imparts a greater redial velocity to the larger particles. The soil particles, which on average are larger than the heavy metal particles, move more rapidly to the separating chamber wall, where they then drop down and are collected as they exhaust through the discharge pipe. The smaller particles are carried upward by the air, which is circulated through the chamber by the main fan. Some of the smaller particles re-enter the separating chamber through baffles, which are located near the bottom of the separating chamber. Eventually most of the smaller particles drop through the fine discharge pipe. The USNA SEPOR system is a bench-scale system with an 18-inch diameter. The system has a soil feed capacity of $800 \mathrm{lb} / \mathrm{hr}$. Feedrate of soil into the SEPOR is controlled by a volumetric screw-type feeder, and can be varied through a wide range.

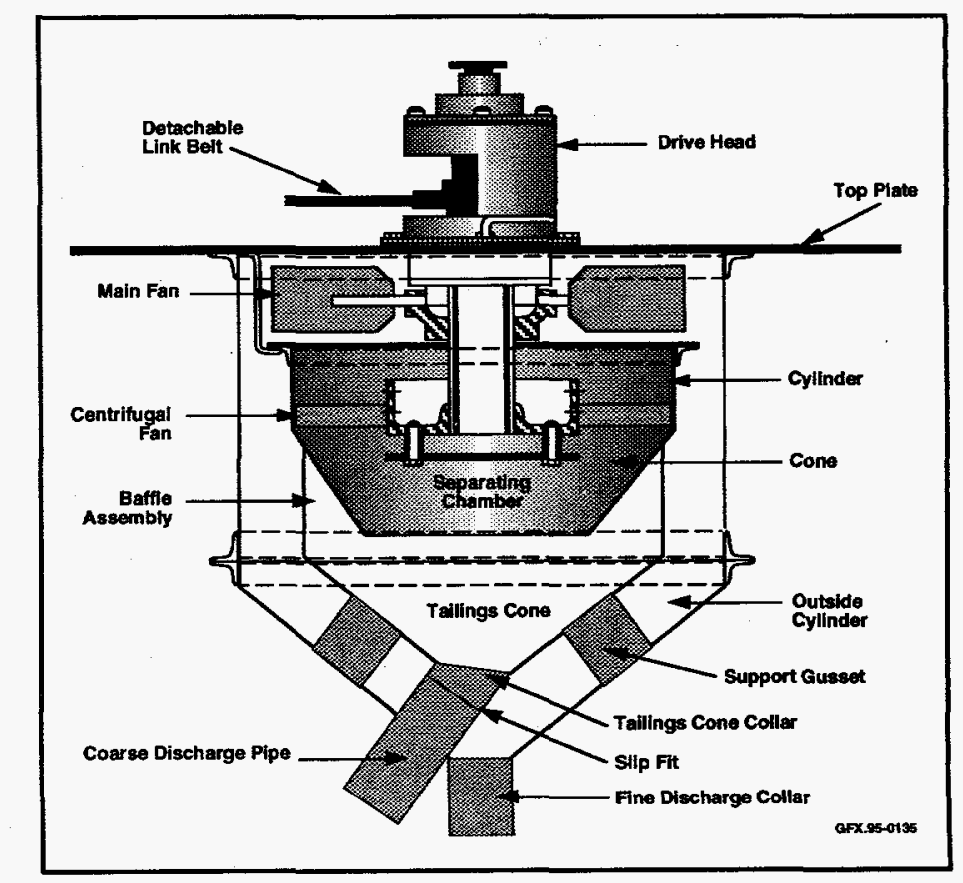

Figure $1.2 \mathrm{~g}$. SEPOR System. 
Sieving of the effluent is being investigated to improve the concentrating effect of the process. Airborne particulate emission is also being studied through the use of an MIE real-time airborne particulate monitor. System design modifications are being implemented in order to minimize the release of airborne particles during testing, as well as minimize soil hangup inside the SEPOR system

For further information, please contact:

S. P. (John) Mathur

Program Manager

U. S. Department of Energy

(301) 903-7922

James Wright

Plume Focus Area Manager

U.S. Department of Energy

Savannah River Operations Office

(803) 725-5608

\section{Creighton Barry}

Program Manager

MSE

(406) 494-7268 


\section{CONTAMINANT PLUMES CONTAINMENT AND REMEDIATION FOCUS AREA}

\subsection{EVALUATION OF SOIL SAWS}

\section{TASK Description}

The Horizontal and Vertical Soil Saws are new technologies being developed to emplace subsurface barriers without excavation. This task will examine the current state of development of the horizontal and vertical soil saws, the types of subsurface soils for which they are suitable, and the costs associated with using the soil saw technology in different soil and geologic conditions. The task will also assess the various grouts that could be used in conjunction with the soil saw technologies.

\section{Technology NeEdS}

Subsurface barriers may be used to prevent the further spread of subsurface contaminants. Some DOE facilities have experienced leaking underground tanks, uncontrolled dumps, and/or leaking controlled dumps. All of these situations can be prevented from causing further environmental harm by emplacing a containment barrier around the contaminated area.

The technology for emplacing full-scale, in situ, subsurface barriers is not yet developed. There are several significant aspects of emplacing in situ barriers that have not yet been reduced to practice. One particular aspect is the need to place grout barriers without excavation. Technologies capable of placing grout around and beneath contaminated areas without excavation need to be developed.

\section{ACCOMPLISHMENTS}

- The horizontal soil saw has undergone preliminary testing by Halliburton NUS.

- The vertical soil saw has undergone preliminary testing by Halliburton NUS.

\section{Collaboration/Technology \\ Transfer}

The horizontal and vertical soil saw technologies are already under development. This task involves defining the progress made and addressing requirements to further develop the technologies. The Morgantown Energy Technology Center, Fernald, Savannah River, Halliburton NUS, FERMCO, and Brown and Root will all collaborate on this task.

Potential users of the soil saw technology are widespread across the DOE Complex and the country as a whole. Because the need is so widespread, subsurface barrier technologies are readily transferrable to containment problems outside DOE. Some candidates for in situ containment systems are uncontrolled dump sites, leaking chemical and fuel storage tanks, and engineered but failing waste disposal facilities.

Once technical criteria have been established, those results will provide technical and economic information for dissemination through presentations and/or publications at national meetings, conferences, workshops, seminars, etc.

For further information, please contact:

Skip Chamberlain

Program Manager

U.S. Department of Energy

(301) 903-7248

James Wright

Plume Focus Area Manager

U.S. Department of Energy

Savannah River Operations Office

(803) $725-5608$

Creighton Barry

Program Manager

MSE

(406) 494-7268 


\section{$1.4 \quad$ SUBSURFACE BARRIERS}

\section{TASK Description}

Subsurface barriers can be used to prevent the spread of contaminants in the soil. This project addresses several aspects of the development of subsurface barriers. First, barrier monitoring technologies will be identified and considered for further development. Second, performance standards for barriers will be developed. Third, technologies for constructing barriers will be field tested under welldefined conditions. The technologies that will be tested include grouts such as polymers, viscous liquids, and flowable grouts. In addition to barrierforming agents themselves, a technique for emplacing a grout barrier under the contaminated soil will also be tested.

\section{TechNology NeEdS}

Subsurface barriers may be used to prevent the further spread of subsurface contaminants. Some DOE facilities have experienced leaking underground tanks, uncontrolled dumps, and/or leaking controlled dumps. All of these situations can be prevented from causing further environmental harm by building a containment barrier around the contaminated area.

The technology for emplacing full-scale, in situ, subsurface barriers is not yet developed. There are several significant aspects of emplacing in situ barriers that have not yet been reduced to practice. Several of these aspects are listed below. Barrier verification and monitoring technologies and performance standards must to be developed, barrier materials must be tested under varying conditions, and barrier emplacement techniques must be developed.

\section{ACCOMPLISHMENTS}

- Several innovative grout technologies have been tested at small scale.

- The horizontal soil saw has undergone initial testing.

\section{Collaboration/Technology Transfer}

These technologies are already under development by several companies and laboratories. This task will work with those entities to further develop the technologies. Sandia National Laboratories (SNL), INEL, Lawrence Berkeley Laboratory, Brookhaven National Laboratory, the City of Richland, Washington, and Golder Federal Services will all collaborate on this task.

Potential users of these technologies are widespread across the DOE Complex and the country as a whole. Because the need is so widespread, subsurface barrier technologies are readily transferrable to containment problems outside DOE. Some candidates for these in situ containment systems are uncontrolled dump sites, leaking chemical and fuel storage tanks, and engineered but failing waste disposal facilities.

Once technical criteria have been established, those results will provide technical and economic information for dissemination through presentations and/or publications at national meetings, conferences, workshops, seminars, etc.

For further information, please contact:

Skip Chamberlain

Program Manager

U.S. Department of Energy

(301) 903-7248

James Wright

Plume Focus Area Manager

U.S. Department of Energy

Savannah River Operations Office

(803) $725-5608$

Creighton Barry

Program Manager

MSE

(406) 494-7268 


\section{TASK Description}

The primary objective of this project is to produce a user-friendly, personal computer-based decision tool for air-sparging application. The decision tool is intended to allow the user to address two issues:

- Assessing the level of applicability of air sparging to site- and contaminant-specific data to determine the applicability of air sparging to a particular remediation scenario.

- Analyzing operating data from existing air sparging systems and evaluating the performance of the systems based on factors such as removal effectiveness and operating efficiency.

The tool will be calibrated and tested against existing data from air-sparging remediation efforts. The decision tool and supporting documentation, including user manuals and a full description of features, will be used to transfer this tool.

\section{Technology Needs}

This project will develop a user-friendly, personal computer-based system for planning, optimizing, applying, and monitoring techniques using airsparging technology. This project will be initiated with development of a review team that will include individuals experienced and knowledgeable in the area of air-sparging technology. Although air sparging is a commonly used technology in industry, optimization of existing applications and determination of the most efficient design, which are products of this decision tool, are avenues this tool will provide to $\mathrm{DOE}$ and the air-sparging industry.

\section{ACCOMPLISHMENTS}

- MSE subcontracted the development of the decision tool to Parsons Engineering Science (PES).
- The Air-Sparging Optimization Tool Project Plan was developed, and project work was initiated.

\section{Collaboration/Technology TraNSFER}

The decision tool and supporting documentation, including user manuals and a full description of the features, will be used to transfer this tool for use by DOE, the U.S. Department of Defense (DoD), other federal agencies, state and local governments, and private industry. This project includes activities involving cooperative efforts and distribution of technical information through presentations and publications.

Existing forums (e.g., National Ground Water Associations's Petroleum Hydrocarbons and Organic Chemicals in Groundwater Conference, and Oregon Graduate Institute's International Air Sparging Conference) will be used to facilitate technology transfer to the public and technical community. Presentations at workshops, conferences, symposia, seminars, and other formal meetings will serve this purpose.

Prospective projects for future use of the decision tool will be identified through interaction with the user community screening coordinators; Dr. Robert Siegrist for DOE Complex sites and Edward Karlalik for industrial sites. It is anticipated by both coordinators that several sites will be able to use the tool for applicability screening or system optimization during the latter portion of the project.

For further information, please contact:

Kurt Gerdes

Program Manager

U.S. Department of Energy

(301) 903-7289 


\section{James Wright}

Plume Focus Area Manager

U.S. Department of Energy

Savannah River Operations Office

(803) 725-5608

\section{Creighton Barry}

Program Manager

MSE

(406) 494-7268 


\section{TASK Description}

The ultimate project goal is demonstrating the economic and technical feasibility of commercializing a biotechnology that uses plants to remediate soils, sediments, surface waters, and groundwater contaminated by heavy metals and radionuclides. See Figure 1.6. This technology, known as phytoremediation, is especially suited to areas of land or water where low concentrations of contaminants are widespread.

Ongoing activities are focused on developing and implementating protocols for evaluating phytoremediation performance for cleanup of soils, sediments, and groundwater at select DOE sites. The soils/sediments task includes a literature search for identification of known or potential contami- nant hyperaccumulating species, hydroponic screening of these species (under controlled laboratory conditions), and evaluating the most promising species performance under field conditions.

Similarly, the groundwater remediation task involves identifying and testing, at laboratory-, bench-, and field-scale, hyperaccumulator performance of various rooted and floating aquatic plants and microalgae, as well as contaminant hyperaccumulation by roots of terrestrial plants.

\section{TeCHNOLOGY NeEDS}

Widespread heavy metal and radionuclide contamination exists in soils and groundwater across the DOE Complex, and much of this contamination is

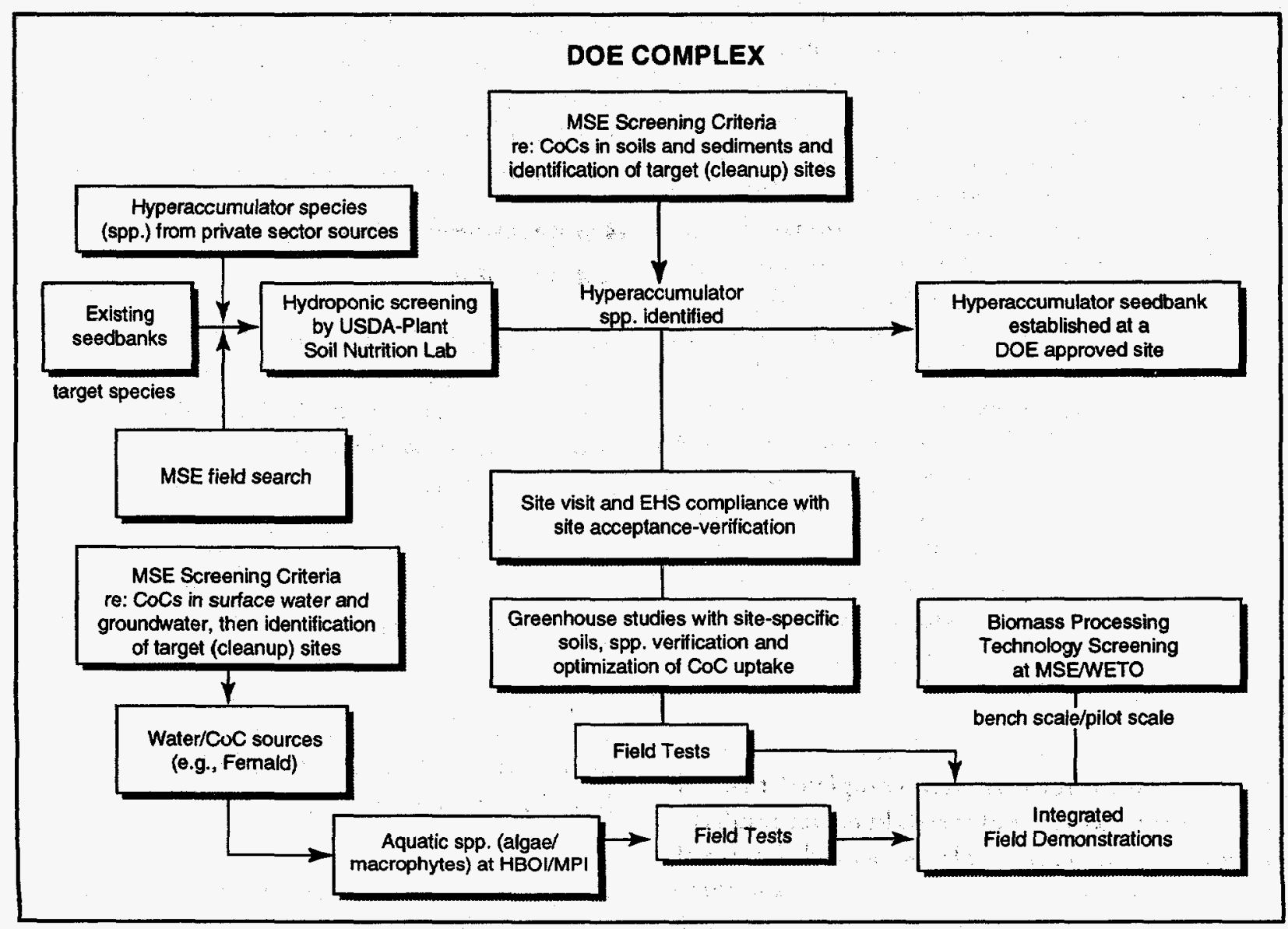

Figure 1.6. Functional overview of biomass remediation system evaluation program. 
present in low concentrations or activity levels. For such low levels of contamination in relatively large quantities of soil and water, removal and storage or remote treatment (such as incineration for soil) becomes extremely expensive. The bioremediation technology proposed could be less expensive than soil removal and treatment given the real extent and topography of the sites under consideration, the problems associated with process-generated fugitive dust emissions, and the investment of energy and money in the soil-moving or water-pumping and treatment processes. Moreover, in situ technology may receive regulatory acceptance more easily than ex situ treatments. Taking advantage of the natural ability of plants to take up stable or radioactive metals is an inexpensive and publicly appealing method by which remediation of low-level contamination can occur.

\section{ACCOMPLISHMENTS}

Feasibility of the approach was initially evaluated by: 1) obtaining biomass samples from plants growing in contaminated soils and water to determine the accumulation of heavy metals/radionuclides, and 2) subjecting the biomass to the Ukrainian Fractionation Separation Technology (FST) to evaluate the effectiveness of this fractionation technology in concentrating and separating heavy metals from the bulk biomass to allow easy disposal of contaminants. The FST results for separation and concentration of nonradioactive cesium and strontium, from hydroponically grown garden peas, into the cell-juice and pulp phases, respectively, were promising. However, the results for FST processing of heavy metals (e.g., cadmium) from terrestrial and aquatic biomass were not successful. Consequently, the FST investigations were terminated, and the work was redirected to comprehensively address the issues associated with commercializing phytoremediation technology.

The following major activities have been completed. First, literature reviews were completed that: 1) documented existence of metals hyperaccumulating terrestrial and aquatic plants needed for timely phytoremediation of soils and water, 2) supported the likely cost-effectiveness of this in situ technol- ogy versus ex situ alternatives (e.g., soil washing), and 3) documented the existence and likely availability of thermal treatment processes for biomass volume reduction/contaminant concentration in ash. Second, field-related protocols were developed and applied for evaluation of uranium uptake by plants grown in contaminated soils at Fernald, Ohio, and at an abandoned uranium mine near Clancy, Montana, as well as heavy metal-contaminated soils near Anaconda, Montana. Third, heavy metal uptake by select aquatic plants (ranging from pond weed-macrophytes to microalgae) was evaluated by Harbor Branch Oceanographic Institute of Ft. Pierce, Florida. Fourth, DOE-OST convened a group of world-class researchers (soil and plant scientists, molecular biologists, etc.) in Santa Rosa, California, in July of 1994 to evaluate basic and applied research issues required to expedite development of phytoremediation technology. Finally, MSE planned and implemented an initial search for naturally occurring, but presently unidentified, heavy metal hyperaccumulation species in the Rocky Mountain West. Essentially, this effort involved plant and soil sampling at abandoned hardrock mine-mill (tailings) sites in southwestern Montana, northern Idaho, and near Leadville, Colorado.

\section{Collaboration/Technology}

\section{Transfer}

MT International of Dublin, Ohio, established a joint venture agreement, the American-Ukrainian Biotech IV (AUB), with the Central Scientific Research Laboratory of Comprehensive Processing of Plant Raw Materials of the Ukrainian Academy of Agrarian Sciences. The Ukrainian Academy of Agrarian Sciences and Berevernik Scientific Research Institute have conducted large-scale soil remediation, implementing a biomass processing system near the radioactive Chernobyl site. American Ukraine Biotech IV provided the laboratoryscale FST system design and personnel necessary for operation. MSE, Inc., established a contract with MT, Inc., to provide access to the Ukrainian technology.

A contract was also established with Harbor Branch Oceanographic Institution, Inc., and Microbial 
Products, Inc., to assist in selecting algae species for study and to produce sufficient quantities of selected species to perform bioremediation evaluations and assess the applicability of FST to algae.

The Uranium in Soils Integrated Demonstration Program participated in the project and worked with MSE, Inc., to perform field demonstrations at Fernald, Ohio.

In February 1995, the United States Department of Agriculture National Soil, Plant, and Nutrition Laboratory at Ithaca, New York, acting under an Interagency Agreement with DOE, began to screen hundreds of plant species for their ability to hyperaccumulate the specific heavy metal and radionuclide contaminants from nutrient solutions that simulate soil conditions at the DOE test sites. The results will be used to select candidate species for field trials during the summer of 1995 .

For further information, please contact:

\section{Kurt Gerdes}

Program Manager

U.S. Department of Energy

(301) 903-7289

\section{James Wright}

Plume Focus Area Manager

U.S. Department of Energy

Savannah River Operations Office

(803) $725-5608$

\section{Creighton Barry}

Program Manager

MSE

(406) 494-7268 


\section{TASK Description}

The Resource Recovery Project (RRP) was established by the DOE to evaluate, test, and demonstrate pilot-scale technologies for reclaiming metals and water from the Berkeley Pit in Butte, Montana. See Figure 1.7. The project is managed by MSE, Inc., at the DOE Western Environmental Technology Office (WETO) located in Butte, Montana.

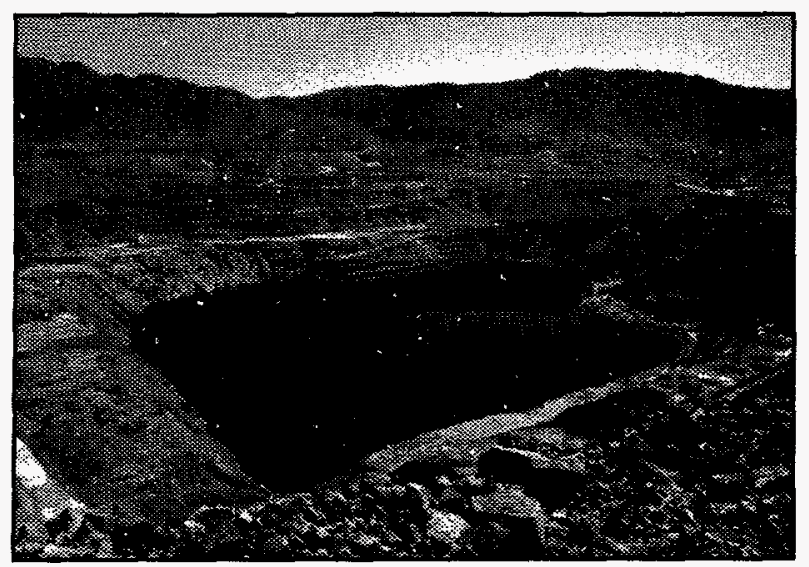

Figure 1.7. The Berkeley Pit, test bed for the Resource Recovery Project.

The project focuses on resource conservation and end-use applications of the recovered resources. MSE has performed a preliminary marketing analysis for recoverable products and has identified potential markets for recovered water and metals.

An inactive open pit copper mine, the Berkeley Pit currently holds over 25 billion gallons of highly acidic water containing metals and other minerals. Approximately 5 million gallons per day of contaminated water flow into the Berkeley Pit from the surrounding surface and groundwater systems. Designated by the EPA as a Superfund site, the Berkeley Pit will contain 56 billion gallons of contaminated water at its projected maximum.

\section{Technology Needs}

Surface and groundwater contaminated with dissolved metals are widespread problems that pose a significant threat to human health and aquatic environments. These threats caused by acid mine drainage have been identified at more than 300,000 abandoned hard rock mines in the United States. Runoff at abandoned mine sites containing acids, metals, and chemicals has contaminated the nation's rivers, streams, lakes, and reservoirs.

Over 75 percent of the nation's Superfund sites are plagued with surface or groundwater contamination. In addition, $D O E$ and $D o D$ have identified heavy metal-contaminated water problems at numerous federally owned facilities and installations.

Technologies demonstrated under the RRP will determine their ability to return contaminated water to a useful state. Products such as copper, zinc, manganese, iron, cadmium, etc., may be recovered for productive use as industrial/materials or used as feedstocks to other industrial processes.

\section{ACCOMPLISHMENTS}

- Negotiated resolution of legal and regulatory issues.

- Completed water access agreement with responsible parties.

- Completed two technology demonstrations.

- Ongoing identification of markets for clean water and recovered products.

- Continued government, industry, and stakeholder partnerships for technology implementation.

- Completed modifications to existing facility to support project. 


\section{Collaboration/TechNology Transfer}

Each year three to five technologies will be demonstrated by the RRP. In FY94, two technologies were demonstrated at the WETO site, and four technologies have been approved for demonstration in FY95.

For further information, please contact:

S. P. (John) Mathur

Program Manager

U.S. Department of Energy, EM-551

(301) $903-7922$

James Wright

Plume Focus Area Manager

U.S. Department of Energy

Savannah River Operations Office

(803) 725-5608

\section{Creighton Barry}

Program Manager

MSE

(406) 494-7268 
TETRA Technologies, Inc., High Density Solids (HDSTM) Process

TETRA Technologies, of Houston, Texas, conducted a demonstration of the patented High Density Solids (HDS ${ }^{\mathrm{TM}}$ ) process in FY94. This improved precipitation process was originally used for metal hydroxides and later expanded to include sulfide precipitation. In contrast to conventional precipitation, the HDS ${ }^{\mathrm{TM}}$ process produces larger particles with less surface energy, resulting in solids that are much easier to dewater by settling and filtration. Improved dewatering characteristics result in lower capital and operating cost when compared to conventional precipitation processes.

The HDS ${ }^{\mathrm{TM}}$ process was specifically configured for Berkeley Pit water to maximize resource recovery (products) and minimize associated by-product wastes. The four-stage process recovered copper sulfide, one gypsum product (including iron and aluminum), zinc hydroxide, and a second gypsum product containing magnesium and manganese. The copper sulfide, zinc hydroxide, and gypsum product containing magnesium and manganese, after drying, are marketable as industrial feedstocks. Although no specific markets were identified for the remaining gypsum product, this material may have potential for industrial use after further upgrading. Effluent water from the process met EPA "Gold Book" standards for heavy metals, i.e., some adjustment in $\mathrm{pH}$ would be required prior to discharge. Water meeting Gold Book standards can be marketed to industrial users as instream/irrigation water or used as municipal water (as a drinking water source).

Key objectives of the RRP were met in this demonstration: recovery of marketable metals and production of usable water.

Vail Research and Technology Corporation and Pulsed Power Technologies, Inc., (Vail/ PPTI) Pulsed Plasma Process
Vail Research and Technology Corporation and Pulsed Power Technologies conducted a demonstration of their pulsed plasma process in FY94.

In the Vail/PPTI process, a contaminated liquid (Berkeley $P$ it water) is continuously pumped through a thick-walled steel chamber where it is subjected to high-voltage, high-power pulses of electrical energy. Energy pulses delivered through a spark gap between closely spaced electrodes immersed in the stream produce ionized plasma (a collection of charged particles) and severe shock waves. In theory this causes chemical bonds to break and dissolved metals to precipitate in elemental form.

Although the demonstration was successfully completed, minimum amounts of water were processed, and the technology produced a relatively small amount of solid samples for analysis. A persistent problem throughout the demonstration was electrode disintegration, attributed to the shock waves, which resulted in mechanical failure.

As a result of this problem, the demonstration did not meet objectives. Too little solid product was collected to perform a preliminary economic analysis or marketability study. Even if sufficient product had been available, a marketability study of the solid product would have been irrelevant due to the presence of electrode fragments. Since metals were not significantly removed, the water failed to meet federal or state discharge standards.

The following technology demonstrations are planned for FY95, and each has the potential to successfully produce marketable metal products and water.

IBC Advanced Technologies, Inc., Highly Selective Molecular Recognition Technology, or “Superlig®"

IBC Advanced Technologies, Salt Lake City, Utah, proposes demonstrating a proprietary molecular 
recognition technology tradenamed "Superlig@" in fixed bed columns to selectively extract iron, copper, aluminum, zinc, manganese, and a mixture of other metals. Superlig@ is based on research awarded the 1987 Nobel Prize in chemistry. The high selectivity of Superlig(B) is based on IBC's unique media that uses proprietary Molecular Recognition Technology tailored to each metal ion desired to be extracted. Superlig ${ }^{\circledR}$ will extract metals from Berkeley Pit water in a series of fixed bed columns, resulting in concentrated metal sulfate brines containing iron, aluminum, manganese, copper, and zinc. These metal sulfate brines can then be processed to recover the metals. The water will potentially be marketable to industrial users and possibly as instream/irrigation water.

\section{Electrochemical Design Associates Rotating} Cylinder Electrodes and Electrochemical Ion Exchange Modules

Electrochemical Design Associates (EDA), of Orinda, California, will demonstrate a process specifically configured for Berkeley Pit water. The company's approach uses two separate, complementary electrochemical technologies to reclaim marketable metals and produce clean water.

The first technology uses a rotating cylinder electrode (RCE) system, which is similar to an electroplating process. Metals are deposited onto the electrode walls, in powder form, where they are scraped off and collected. These RCE devices can be electrically tuned to selectively strip metals as relatively pure powders from mixed heavy metalbearing wastestreams. The RCE system can work with dilute solutions and still maintain electrochemical efficiency.

The second technology, an electrochemical ion exchange (EIX) process, can strip both anions and cations from very dilute solutions. A general ion exchange process involves a reversible interchange of one kind of ion (ion exchange resin) present on an insoluble solid (media) with another of like charge present in a solution surrounding the media. The EIX process uses an ion exchange resin combined with an electrically reversible electrode.
During the stripping process, the electrode drives ions into the resin more efficiently than a simple ion exchange; the resin is then regenerated by reversing the current.

ChromatoChem, Inc., and International Technology Corporation Solid Phase Extraction (SPE) Process

The patented Solid Phase Extraction (SPE) process was developed by ChromatoChem, of Missoula, Montana. Metal-chelating groups are often used in place of ion exchange resins in ion exchange processes. Because the metal-binding functional groups are bound at the surface of the media, it is necessary for the exchanging ions in solution to pass through a rate-limiting stagnant boundary layer at the liquid-solid interface. As a result, ion exchange extraction of metals requires relatively long residence times (in minutes). ChromatoChem's approach to the problems of diffusion-limited adsorption was to covalently bind a long hydrophilic linking molecule to the surface of chromatographic silica. A chelating agent with an affinity for metal ions is attached to the end of the linking molecule. The attached chelating agent extends approximately $50 \mathrm{Angstroms}$ away from the solid surface and is actually in the silica support pore space where fluid is being treated. This significantly reduces diffusion limitations and provides for fast transfer (in seconds) of the metal ions from the bulk solution to the media. ChromatoChem's process is capable of achieving kinetics that are orders of magnitude greater than conventional ion exchange, resulting in considerable capital cost savings.

Different dissolved metals exhibit a range of binding strengths with the chelating agent. These different binding strengths allow the dissolved metals to be selectively removed from a metals-laden stream. As a mixed metals solution is fed to a column containing the media and ion-exchange resins, all metals (except sodium, calcium, and magnesium, which are nontoxic and unregulated) are initially captured. Once the column is saturated, the more tightly bound metals displace the less tightly bound metals until only the most tightly bound metal is present. Thus, metals in a complex feed solution 
can be separated into side streams of sequentially lower binding strengths.

Metals to be recovered as pure, concentrated metalsulfate streams include copper, aluminum, zinc, and manganese. These products are known to have existing markets. Resulting water should be suitable for use by industrial users and possibly for use as instream/irrigation water.

For further information, please contact:

S. P. (John) Mathur

Program Manager

U.S. Department of Energy, EM-551

(301) 903-7922

\section{James Wright}

Plume Focus Area Manager

U.S. Department of Energy

Savannah River Operations Office

(803) $725-5608$

Creighton Barry

Program Manager

MSE

(406) 494-7268 


\section{TASK DESCRIPTION}

The purpose of this project is to determine to what extent a biological barrier grown using ultramicrobacteria (UMB) can plug porous media and impede the flow of subsurface water, either uncontaminated or contaminated with organic or inorganic substances. The scope of this project for FY95 initially consists of experimenting with pilotscale test chambers. Larger-scale tests that build on pilot-scale results will then be performed.

To test the effectiveness of biological barriers, a two-tiered approach was undertaken. The first goal was to prove that UMB could plug porous media and form a barrier. The criterion for a successful barrier was a 90 percent reduction in the flow rate. The second goal was to test the integrity of the barrier by challenging it with inorganic and organic contaminants. Again, success was based on a 90 percent reduction in the flow of the contaminated stream.

This project takes results from previous research and builds on these results. Some basics, such as bacteria starvation and barrier formation, are performed using techniques discovered during previous research. Other items, such as long-term barrier maintenance, have not been studied in detail. Also, the literature does not record any instances where a biological barrier was challenged with contaminated water. This project will attempt to answer questions regarding these and other aspects of biological barriers.

\section{Technology NeEdS}

Organic and heavy metal contamination exists in soils and groundwater across the DOE Complex. Ultramicrobacteria technology has the potential to contain these pollutants while a more permanent solution is found. If this technology is successful, biobarriers to subsurface flow can prevent the movement of contaminated groundwater. There is also potential for UMB technology to assist in the biodegradation of organics and sequestration of heavy metals that are difficult to reach by standard remediation techniques.

\section{ACCOMPLISHMENTS}

To test the effectiveness of biobarriers, pilot-scale test chambers were designed and fabricated. These test chambers were fabricated from 6-inch diameter, 3-foot long clear plastic pipe. See Figure 1.9. The chambers were filled with sand and inoculated with UMB; a nutrient solution was then passed through the chambers. Within a week, the resulting plug reduced the flow to less than 10 percent of the original flow rate. However, barrier effectiveness started degrading after a few weeks due to the presence of sulfate-reducing bacteria.

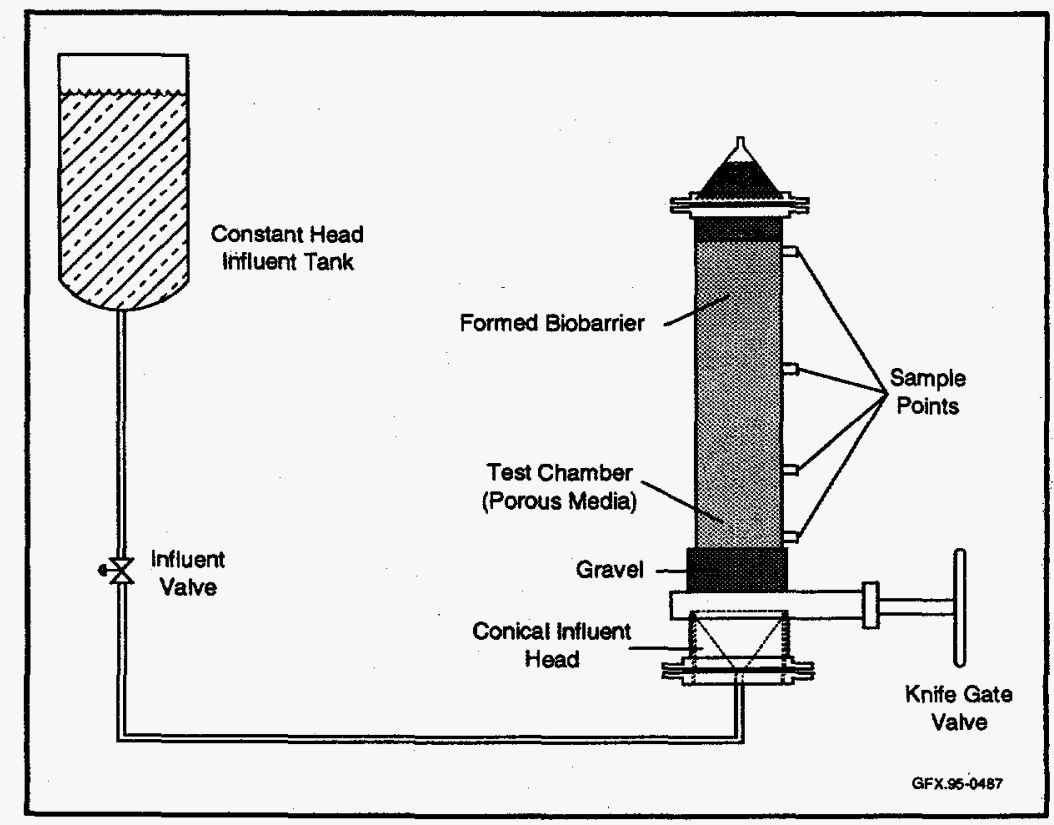

Figure 1.9. Pilot-scale UMB test chamber. 
Sulfate was eliminated from the nutrient media, and the chambers were repacked with sand, and new barriers were formed. After allowing the flow rate to stabilize, one of the barriers was challenged with an aqueous solution of one part per million strontium. The barrier did not degrade during a continuous 2month challenge. An aqueous carbon tetrachloride challenge is planned for FY95.

Larger-scale test chambers have been fabricated that allow injection of UMB and nutrients independent of groundwater flow. Barriers will be formed, and challenge tests will be performed during FY95 in test chambers that hold 20 times the volume of the pilot-scale chambers.

\section{Collaboration/Technology Transfer}

MSE is collaborating on this project with the Center for Biofilm Engineering (CBE). The CBE is a research facility located on the Montana State University Campus in Bozeman, Montana, and is sup- ported principally by the National Science Foundation. The $\mathrm{CBE}$ mission focuses on the advancement of technology and education for understanding the control and exploitation of biofilm processes.

For further information, please contact:

Dr. Rashalee Levine

Program Manager

U.S. Department of Energy

(301) $903-7920$

James Wright

Plume Focus Area Manager

U.S. Department of Energy

Savannah River Operations Office

(803) 725-5608

\section{Creighton Barry}

Program Manager

MSE

(406) 494-7268 


\section{TASK DESCRIPTION}

The production of uranium fuels and weapons materials has caused a number of difficult environmental problems. Past operational practices have resulted in the release of uranium and other heavy metals into groundwater at DOE sites and other federal facilities. This groundwater contamination is often mobile and spreads over large areas and distances, posing a risk to human health and the environment.

The In Situ Plume Remediation Program (ISPRP) will demonstrate the application of commercial in situ uranium mining technologies to the remediation of groundwater contaminated with uranium and other heavy metals. In situ uranium mining methods include hydraulic control and groundwater sweeping through the use of extraction and reinjection wells. Well fields employing these techniques are much more effective than simple pump-and-treat systems. A demonstration of the technologies will be carried out at an appropriate DOE site.

\section{ACCOMPLISHMENTS}

The ISPRP is currently developing a plan for demonstrating uranium recovery technologies at the DOE's Fernald, Ohio, site. The target for demonstration is uranium-contaminated groundwater in an area known as the South Plume. An extraction well and water treatment system is currently being designed for remediation of the South Plume. The design of this system is being evaluated for potential inclusion of re-injection wells. If this evaluation is favorable, well fields will be designed and installed as an integrated extraction and re-injection system. Hydrogeologic modeling indicates that this approach will be much faster and more efficient than conventional pump-andtreat remediation.

\section{Technology Needs}

Uranium contamination of groundwater is a major environmental problem. Technology needs exist for groundwater control, extraction, enhanced recovery, and in situ stabilization. These needs are closely related to conditions encountered in commercial in situ uranium mining. The ISPRP seeks to improve the cost-effectiveness of groundwater remediation through the implementation of existing commercial in situ mining technologies.

\section{Collaboration/Technology Transfer}

The ISPRP is administered by the DOE-OST through WETO. The program is actively collaborating with DOE's Fernald office and FERMCO (Fernald Operating Contractor). The program is collaborating with the mining industry, particularly with Power Resources, Inc., the largest domestic producer of uranium through in situ means.

For further information, please contact:

Kurt Gerdes

Program Manager

U.S. Department of Energy

(301) 903-7289

James Wright

Plume Focus Area Manager

U.S. Department of Energy

Savannah River Operations Office

(803) 725-5608

Creighton Barry

Program Manager

MSE

(406) 494-7268 


\section{Task Description}

Plasma waste remediation testing began at the DOE's WETO facility with the initiation of an EPA Superfund Innovative Technology Evaluation (SITE) Program project for testing Retech, Inc.'s plasma centrifugal furnace (PACT-6, formerly the PCF-6) in August 1988. The PACT- 6 was installed at WETO during the summer and fall of 1989 , and system startup began on October 20, 1989.

The PACT-6 system, consists of a sealed, rotating tub in which a plasma torch supplies thermal energy to melt inorganic materials and combust organic materials. The ultimate products of the system are a glass-ceramic solid and treated flue gas. The solid has been found to meet the leachability requirements of the EPA Toxicity Characteristic Leaching Procedure (TCLP) and the Nuclear Waste Glass Product Consistency Test (PCT). The flue gas is treated to meet Montana and Idaho emissions requirements.

Shakedown testing and seven PACT-6 test campaigns have been completed at the WETO. The shakedown period of the furnace took nearly 20 months. During this period, MSE learned 1) how to configure the plasma torch for air operation, 2) how to operate the furnace for extended periods, 3 ) how to obtain valid data from the operation, and 4) the operating envelope of the furnace.

The EPA SITE test occurred during the week of July 20,1991 . This test consisted of trial burn testing of the PACT-6, during which copper mill tailings laden with Resource Conservation and Recovery Act (RCRA) metals and mixed with diesel fuel spiked with hexachlorobenzene were processed. The test resulted in a mean destruction efficiency of the hexachlorobenzene for the three replicate tests of between 99.9968 and 99.9999 percent, and the solid product was found to meet TCLP criteria.

The next two test campaigns addressed the ability of the PACT -6 to process a suite of INEL Radioactive
Waste Management Complex (RWMC) simulated feedstocks. These tests processed mixtures of soils, metals, combustibles, and sludges that simulated the buried wastes.

The 1991 RWMC tests established that the PACT6 could process the feeds and obtain a solid product that passed TCLP and achieve organic destruction similar to that established in the EPA trial burns.

The RWMC test campaign was re-established in September 1992 under the former Buried Waste Integration Demonstration (BWID) Program to complete the tests planned in the RWMC experimental design. From the analytical results of four BWID tests and analyses of subsequent tests in which cerium was not fed to the system, the elemental closure of the cerium in the system was found to be 73 percent. Since only trace amounts of cerium were found in the off-gas system and in the scrubber liquor, it is felt that the cerium partitioned to the solid product, and the low closure was due to inadequate sampling of the solid product retained in the primary chamber.

A second part of the BWID tests processed sludges in the PACT-6. Four sludges were tested: one contained organics, including greases, Texaco regal oil, and carbon tetrachloride; a second sludge contained high concentrations of inorganic nitrates; and the final two sludges consisted of inorganic hydroxides and sulfates mixed into soils consisting of varying proportions of sand and clay. As expected, all of the solid products passed TCLP, the destruction of organics was complete, and the high nitrate sludges resulted in a high concentration of NOx in the off-gas, which, in a full-scale facility, would require some method of treatment prior to discharge.

Two test projects were performed for the U.S. Army. In one test, classified proximity fuzes were processed. It had been found previously that these fuzes could not be made nonrecognizable by incineration using a rotary kiln. The PACT -6 rendered the fuzes 
into an homogeneous slag product that met the needs of the project.

The other U.S. Army project processed ordnance; smoke grenades, artillery simulators, tracer bullets, and star shells were among the items processed. The test results showed the devices could be processed by the PACT -6 with few problems and that the product was again a nonleachable slag.

The RWMC at the INEL has a waste site designated as PIT-9. Under a DOE competitive solicitation, two groups were chosen to perform proof-of-process (POP) testing of technologies proposed for the remediation of PIT-9. The Retech, Inc., plasma treatment technology was proposed by one group, and part of the POP test was performed at WETO using the PACT -6 .

The POP test was performed in November of 1993. Feeds processed were similar to those processed during the RWMC and BWID tests, including high organic and high nitrate sludges, and a simulated PIT-9 feed that consisted of INEL soil, carbon steel, wood, and three sludge formulations. Ceric oxide was blended into the feed to simulate plutonium. Carbon tetrachloride and trichloroethane were added as chlorinated solvent spikes to allow a chlorine balance to be made.

The PACT- 6 processed 31,955 pounds of feed at an average rate of $319 \mathrm{lb} / \mathrm{hr}$ during the POP test. System availability was 63 percent during the test time of 160 hours. Cerium mass balance closure was 119 percent, with the major uncertainty due to cerium holdup in the residual material (skull) left in the primary chamber.

The most recent test campaign was for the U.S. Army Corps of Engineers Construction Engineering Research Laboratory (CERL). Its purpose was to replicate testing done with a 1.5-foot, batch plasma furnace at Retech's Ukiah, California, facility. That project, executed with funding from the DOE Minimum Additive Waste Stabilization (MAWS) Program, established the ability of the plasma system to process wastes containing very high concentrations of metals in an oxidizing environment. The CERL program established the effects of scaling up to the PACT-6 level and the upper limits of throughput when feeding materials with high concentrations of metals.

\section{Technology Needs}

A thermal treatment technology is needed that can handle a wide variety of radioactive and hazardous waste mixtures; completely combust organic materials; significantly reduce the waste volume; and provide a stable, leach-resistant, long-lasting, final waste form.

\section{Collaboration/Technology Transfer}

The PACT- 6 was developed through an industrial partnership with MSE, Inc., DOE, DoD, and Retech, Inc.

For further information, please contact:

Grace Ordaz

Program Manager

U.S. Department of Energy

(301) 903-7440

Jeff Ruffner

Program Manager

MSE

(406) 494-7412 


\subsection{WETO THERMAL TESTING FACILITIES}

\section{Plasma Facility Description}

MSE, as the operating contractor for DOE's WETO facility in Butte, Montana, is applying its engineering and operations expertise to evaluate the use of plasma technology for the thermal treatment of hazardous and radioactive waste. Plasma technology can treat heterogeneous unconsolidated feeds, including organic materials, sludges, metals, rock, concrete, soils, and other types of waste, such as whole items that contain hazardous organic/inorganic materials as part of their components. Plasma technology can be used to treat heterogeneous nonsorted waste directly or can be used as part of an integrated waste treatment system to stabilize the final waste from other treatment processes.

Two plasma processing systems are currently used for testing at WETO. The first system is the demonstration-scale Retech, Inc., plasma arc centrifugal treatment (PACT-6) system. The PACT-6 is equipped with a $500-\mathrm{kW}$ torch and is capable of continuous treatment of material at rates up to 350 $\mathrm{lb} / \mathrm{hr}$. The second system is the bench-scale smallscale plasma furnace (SSPF). The SSPF is equipped with a $160-\mathrm{kW}$ torch and will treat 10 to 20 pounds of material per batch.

\section{$\underline{\text { PACT-6 }}$}

The PACT- 6 system, shown in Figure $1.12 \mathrm{a}$, is a transferred electric arc process designed to destroy organic material through high-temperature oxidation and immobilize inorganic material into a low leachable glass ceramic matrix. The process uses a rotating reactor well (tub) inside a primary chamber into which feed material containing hazardous materials is fed and heated by a continuous electric arc in an oxygen-enriched atmosphere.

The major components of the PACT -6 are:

- feeders;

- primary chamber with rotating reactor tub;

- 500-kW-rated transferred arc plasma torch;

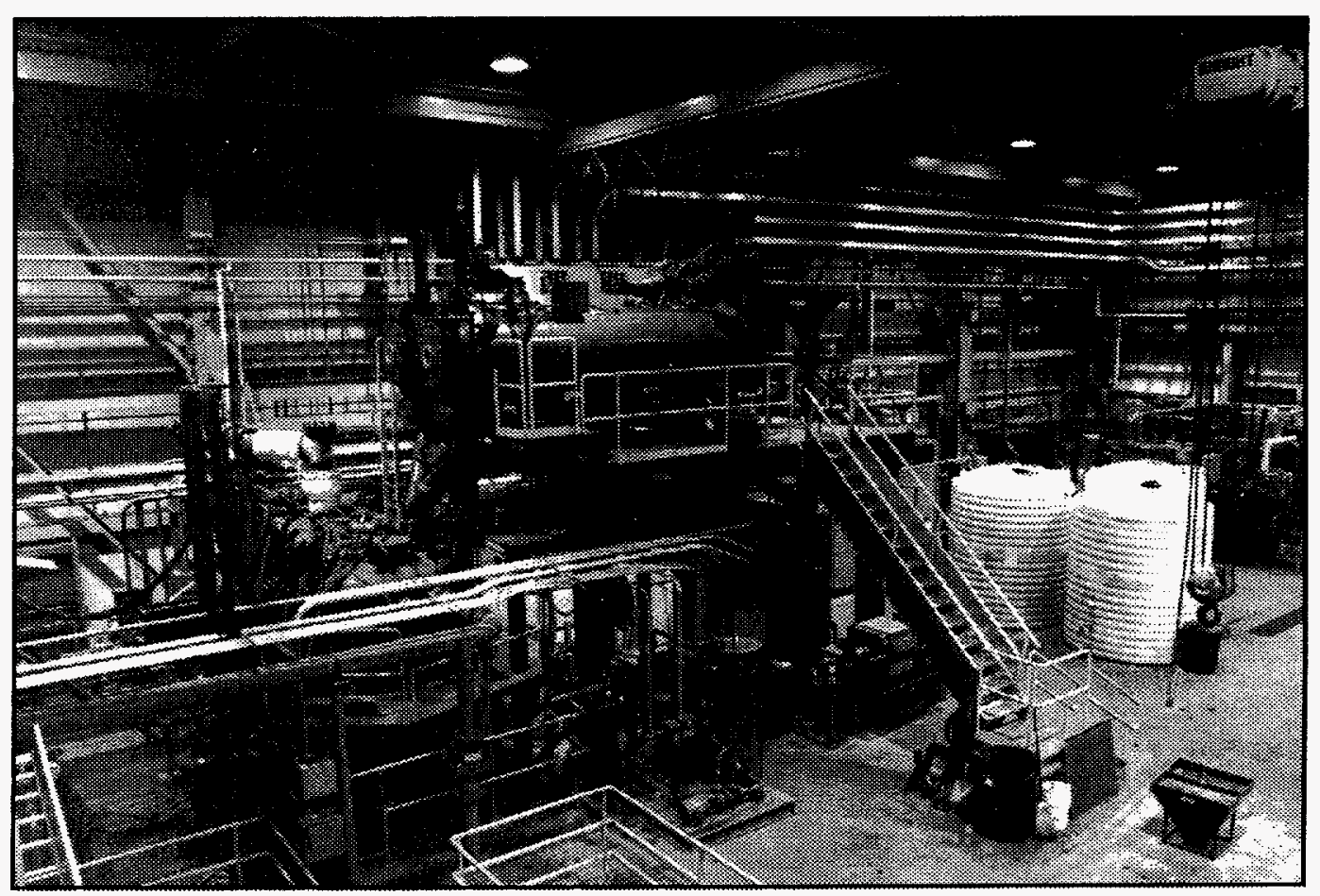

Figure 1.12a. WETO PACT-6 System. 
- secondary combustion chamber (SCC);

- slag collection chamber;

- pollution control and exhaust equipment; and

- exhaust gas analysis system.

Typical process operating conditions of the PACT-

6 system are:

- feed rate up to $350 \mathrm{lb} / \mathrm{hr}$ (nominal $\approx 250 \mathrm{lb} / \mathrm{hr}$ );

- plasma gas (air) flow rate $\approx 23$ standard $\mathrm{ft}^{3} / \mathrm{min}$ (scfm);

- drive chamber nitrogen purge $\approx 9.5 \mathrm{scfm}$;

- feeder air purge $\approx 30 \mathrm{scfm}$;

- plasma torch centerline temperature $\approx 15,000$ to $20,000^{\circ} \mathrm{F}$ (estimated);

- plasma torch power $\approx 400$ to $500 \mathrm{~kW}$;

- plasma torch voltage $\approx 400$ to 500 volts;

- plasma torch current $\approx 1,000$ amps (maximum);

- primary chamber pressure $\approx 10$ to 30 inches in a water column gauge vacuum;

- primary chamber oxygen flow rate $=18 \mathrm{scfm}$;

- molten material temperature $\approx 2,500{ }^{\circ} \mathrm{F}$ (estimated);

- primary chamber gas temperature $\approx 2,000{ }^{\circ} \mathrm{F}$ (minimum);

- $\mathrm{SCC}$ gas temperature $\approx 1,800^{\circ} \mathrm{F}$ (minimum);

- afterburner heat input to the secondary chamber $\approx 540,000 \mathrm{Btu} / \mathrm{hr}$;

- SCC gas residence time of 2 seconds minimum; and

- stack gas oxygen maintained at 5 to 15 percent by volume of total flow.

Major components of the pollution control and exhaust system are:

- quencher;

- packed bed contact condenser/absorber/nucleator;
- scrubber liquid chiller;

- high-energy atomizing scrubber/agglomerator;

- demister;

- electric heater;

- baghouse;

- roughing filter, high-efficiency particulate air filter (HEPA), activated carbon bed, HEPA filter combined filtration train;

- induced draft blower;

- off gas sampling station;

- electric reheater; and

- NOx catalytic reactor.

Pollution control system operating conditions are:

- combustion gas inlet temperature $\approx 1,500$ to $2,000^{\circ} \mathrm{F}$;

- scrubber liquid maintained at a $\mathrm{pH}$ of 8.5;

- HEPA filter rated at 95 percent removal efficiency at 0.30 micron particulate size;

- exhaust stack particulate nominal content $\approx$ 0.003 grains/dry standard $\mathrm{ft}^{3}$;

- NOx reduction to 500 to 1,000 parts per million; and

- gas flow rate $\approx 70$ to $250 \mathrm{scfm}$.

\section{$\underline{\text { SSPF }}$}

The SSPF, shown in Figure 1.12b, uses a $160-\mathrm{kW}$ plasma torch as a heat source for the thermal treatment of feed materials consisting mainly of inorganic materials and possibly small amounts of organics. The inorganic material is melted by the heat produced from the plasma torch, and the organics are destroyed through high-temperature oxidation. The SSPF thermal treatment process converts the inorganic material into a chemically inert and stable glass and crystalline product.

The major components of the SSPF are:

- main chamber; 


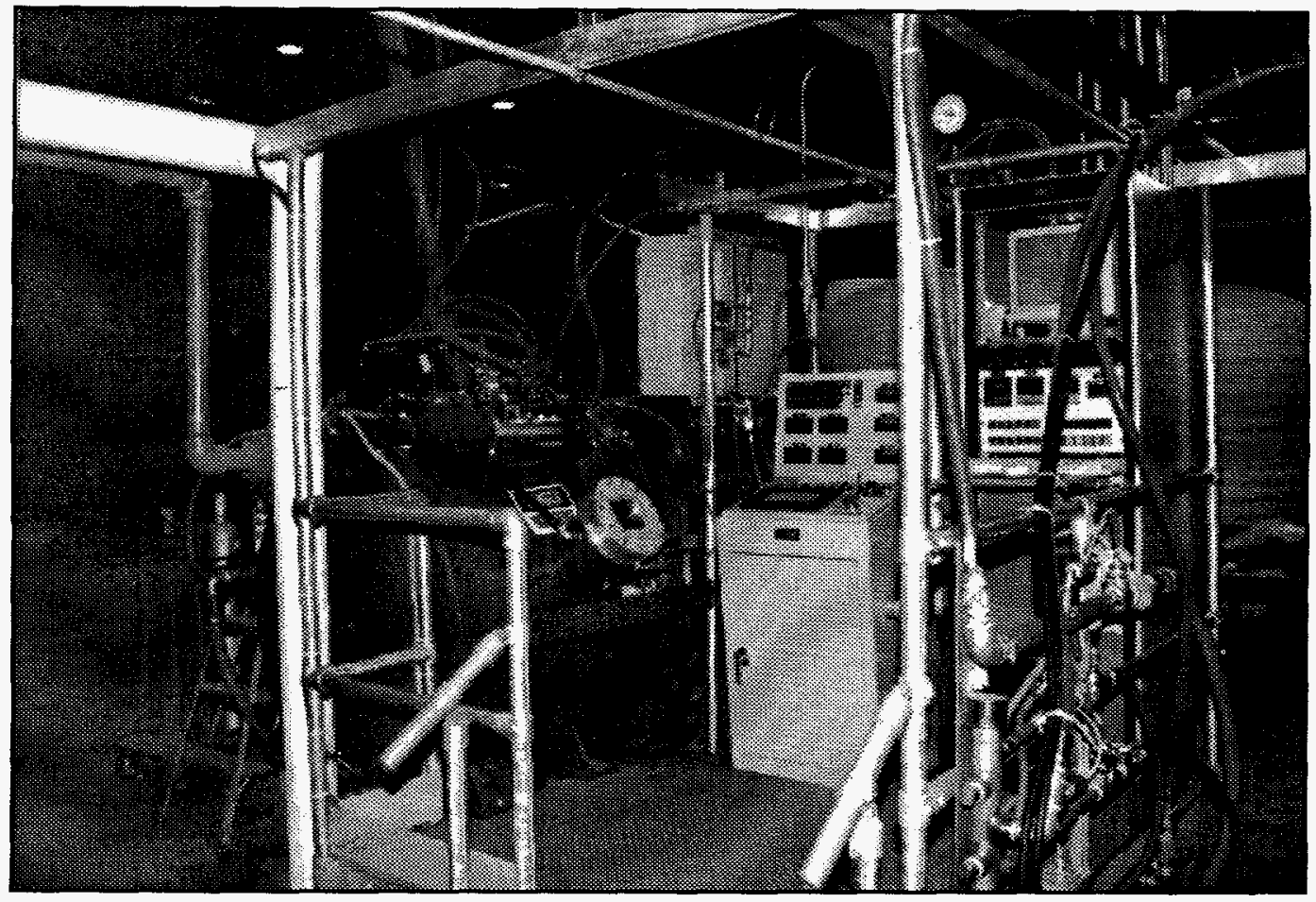

Figure 1.12b. WETO small-scale plasma furnace.

- 160-kW rated transferred arc plasma torch;

- SCC;

- baghouse; and

- induced-draft fan.

The SSPF is operated in a batch mode, i.e., the SSPF crucible (approximately $0.25 \mathrm{ft}^{3}$ ) is loaded prior to torch startup with 15 to 20 pounds of feedstock. It is expected to take 1 to 2 hours of torch processing time to melt and fully oxidize the inorganic material.

Typical process operating conditions of the SSPF system are:

- plasma gas (air) flow rate $\approx 5$ standard $\mathrm{ft}^{3} / \mathrm{min}$ $(\mathrm{scfm})$;

- plasma torch centerline temperature $\approx 15,000$ to $20,000^{\circ} \mathrm{F}$ (estimated);

- plasma torch power $\approx 160 \mathrm{~kW}$;

- plasma torch voltage $\approx 400$ volts (maximum);

- plasma torch current $\approx 400$ amps (maximum);
- main chamber pressure $\approx 10$ to 30 inches in a water column gauge vacuum;

- main chamber oxygen flow rate $\approx 1$ to $10 \mathrm{scfm}$;

- molten material temperature $\approx 2,800{ }^{\circ} \mathrm{F}$ (estimated);

- main chamber gas temperature $\approx 2,000^{\circ} \mathrm{F}$ (minimum);

- $\mathrm{SCC}$ gas temperature $\approx 1,800^{\circ} \mathrm{F}$ (minimum);

- afterburner heat input to the SCC $\approx 120,000$ Btu/hr; and

- SCC gas residence time of 2 seconds minimum.

\section{Technology Needs}

Thermal treatment technology facilities are needed that can demonstrate the capabilities of plasma technologies. The ability of plasma technology to handle a variety of radioactive and hazardous waste mixtures, completely combust organic materials, significantly reduce the waste volume, and provide a stable, leach-resistant, long-lasting, final waste 
form needs to be proven to DOE remediation and cleanup sites.

\section{ACCOMPLISHMENTS}

Plasma waste remediation testing began at WETO with the initiation of an EPA SITE project for testing Retech's plasma centrifugal furnace (PACT6, formerly the PCF-6) in August 1988. The PACT- 6 was installed at WETO during the summer and fall of 1989 , and startup began on October $20,1989$.

Shakedown testing and seven PACT-6 test campaigns have been completed at WETO. During this period, MSE learned: 1) how to configure the plasma torch for air operation, 2) how to operate the furnace for extended periods, 3) how to obtain valid data from the operation, and 4) the operating envelope of the furnace.

The ultimate products of the PACT -6 system are a glass-ceramic solid and treated flue gas. The solid has been found to meet the leachability requirements of the EPA Toxicity Characteristic Leaching Procedure (TCLP) and the Nuclear Waste Glass Product Consistency Test (PCT). The flue gas is treated to meet Montana and Idaho emissions requirements.
The SSPF was installed and commissioned in March of 1995. Shakedown and performance testing will be performed next, then the SSPF will be used for various screening test campaigns.

\section{Collaboration/TEchNology}

\section{Transfer}

The PACT- 6 was developed through an industrial partnership of MSE, Inc., DOE, DoD, and Retech, Inc.

The SSPF was developed by MSE, Inc., with funding from $\mathrm{DoD}$.

For further information, please contact:

Grace Ordaz

Program Manager

U.S. Department of Energy

(301) $903-7440$

Jeff Ruffner

Program Manager

MSE

(406) 494-7412 


\subsection{PLASMA TESTING AND SUPPORT}

\section{TASK DEscription}

A major goal of the Mixed Waste Program is to develop high-temperature vitrification capabilities that will allow a broad range of wastes to be converted into stable, leach-resistant glass and ceramic (glassy slag) waste forms. Plasma technology, one method that was previously evaluated by the Mixed Waste Program, produced an excellent slag waste form that required minimal feed material preprocessing and additives. Continued evaluation and development of high-temperature vitrification processes is being performed by two efforts: 1) the purchase of an Electro-Thermal Processing System, and 2) the purchase of the Plasma Arc Centrifugal Treatment (PACT-6) system.

Electro-Thermal Processing System Purchase

Plasma processing using a rotating crucible/hearth (in the form of the PACT-6) has been performed at WETO since 1989. During the course of the various test series completed using the PACT -6 , the mixing/agitation derived from the crucible rotation was thought to provide a significant portion of the conditions necessary to fully oxidize the inorganic material. The rotation is also thought to provide good heat and mass transfer for the melting of material as the material is fed into the molten pool. Confirmation of the contribution of rotation to material oxidation and melting requires a thermal processing system that uses a different form of mixing/agitation.

A second area of investigation is the production of high quality, glass-ceramic matrix slag while organic material (if present in the waste material) is destroyed. The PACT -6 produces high-quality slag during normal operations. The questions are: 1) whether other types of electrically driven thermal treatment equipment can produce similar highquality slag products and 2) what processing conditions are necessary for operation. Therefore, a specification will be written, proposals will be solicited, and a system will be procured and installed at the WETO facility in Butte, Montana, to address these questions.

\section{PACT-6 Purchase}

The PACT- 6 system is the keystone of the thermal testing activities currently performed at WETO. The PACT- 6 was furnished by Retech, Inc., in 1990 for joint DOE and EPA testing. Retech, Inc., initially provided the equipment at no cost to the Government. During that time, tests were performed for the EPA SITE Program and BWID. After this initial period, a lease agreement between MSE and Retech, Inc., was instituted with the lease payments applied to the purchase price.

Since installation, improvements to the PACT- 6 system have totaled $\$ 8 \mathrm{M}$, of which $\$ 6 \mathrm{M}$ has been contributed by non-DOE Government agencies and industry. Some of the U.S. Army tests have used feed formulations provided from the Minimum Additive Waste Stabilization (MAWS) Program, directly benefiting scaleup efforts from earlier tests conducted on the PACT-1.5 at the Retech, Inc., facility. Leveraging of capital and operating dollars has been approximately 4 to 1 for every DOE-OST dollar spent. This leveraging ratio will increase as the DoD continues to perform additional testing on the PACT- 6 system during the next 2 years.

\section{Technology Needs}

A thermal treatment technology is needed that can handle a wide variety of radioactive and hazardous waste mixtures, completely combust organic materials, significantly reduce waste volume, and provide a stable, leach-resistant, long-lasting, final waste form. 


\title{
ACCOMPLishments
}

The PACT -6 purchase was completed at the end of January 1995. DOE owns the equipment, and it is a permanent WETO fixture.

The Electro-Thermal Processing system specification was created, and procurement activities were initiated. An announcement was published in the Commerce Business Daily (CBD) in March of 1995 seeking qualified vendors.

\section{Collaboration/TECHNOLOGY}

\section{Transfer}

The Electro-Thermal Processing system will be developed through an industrial partnership with the selected vendor, MSE, and DOE.

For further information, please contact:

\author{
Alison Johnson \\ Program Manager \\ U.S. Department of Energy \\ (301) 903-7923 \\ Julie Conner \\ Mixed Waste Focus Area Manager \\ U.S. Department of Energy \\ Idaho Operations Office \\ (208) 526-0648 \\ Jeff Ruffner \\ Program Manager \\ MSE \\ (406) 494-7412
}




\subsection{CONTROLLED EMISSIONS OFF-GAS DEMONSTRATION}

\section{TASK Description}

The Controlled Emissions Off-Gas Demonstration Project was initiated in an effort to address public concerns and reduce emissions from planned thermal treatment processes. As currently outlined, this project is a two-phase demonstration: Fiscal Year 1995 (FY95) activities will focus on demonstrating key technologies required for a controlled emissions demonstration system, and FY96 activities will focus on assembling these technologies into an integrated system for demonstration. Final integrated systems pilot-scale testing will be performed at WETO during FY96.

This project will initially install and demonstrate at WETO several technologies key to the concept of a controlled emissions gas cleanup system in FY95.

A Thermatrix, Inc., flameless oxidizer will be installed in the Plasma Arc Centrifugal Treatment (PACT-6) system off-gas train. In this configuration, the oxidizer will have the capability of processing gas from the primary chamber of the PACT- 6 for extended destruction and removal efficiency (DRE) tests. The oxidizer will be used as an alternative to a gas-fired secondary combustion chamber (SCC) and will provide a reduction in off-gas flows. Thermatrix, Inc., will provide the technology at no cost; the project will pay for all resting and analysis.

A high-temperature ceramic blowback filter will be installed in the small-scale plasma furnace (SSPF) off-gas train and will demonstrate the ability of these high-temperature filters to remove particulate from the off-gas stream of a plasma incinerator prior to acid gas scrubbing.

The Diagnostic Instrumentation and Analytical Laboratory (DIAL) of Mississippi State University, Science Applications International Corporation (SAIC), and SNL will be involved in demonstrating advanced analytical instrumentation that is in the development stage. The initial demonstration will be at the STAR center in Idaho Falls, Idaho, with eventual demonstration on the plasma units at WETO. The goal of this project is twofold, 1 ) the development of these units will be directed to a production-type of equipment, and 2) the system will be used for process control.

A mass spectrometer-based continuous emissions monitoring system (MS-CEMS) will be demonstrated at WETO and will analyze gases from the primary and secondary combustion chambers of the PACT-6. This system will be similar to one installed at the Marine Shale Processing Facility in New Orleans, Louisiana. At Marine Shale, the system has been demonstrated to be capable of detecting carbon tetrachloride at the part per billion level, which relates to a DRE of at least 99.99 percent. After demonstration at the WETO facility, the instrument will be installed on the PIT-9 system at the Radioactive Waste Management Complex (RWMC) at INEL. Lockheed will purchase the unit for the demonstration; the project will pay for all testing and analysis.

Also, a monoethanolamine (carbon dioxide) off-gas capture system, along with an oxygen and nitrogen off-gas membrane separation system will be specified, procured, and tested during FY96, as part of the integrated systems test.

The Controlled Emissions Off-Gas Demonstration Project has two major activities planned for FY97:

1) final integrated systems testing, and 2) definitive design of a final off-gas system to be installed at a specific DOE site.

Systems optimization tests will be performed on the controlled emissions off-gas system. All subcomponents of the system will be tested in detail, and the overall systems operating envelope will be established; this will include any final configurations required to establish the most efficient operation of the system. A test report, including recommendations, will be developed and issued upon completion of the test. 
The definitive design of a controlled emissions offgas system for a specific installation within the DOE Complex will be developed. MSE will be the lead contractor to develop a process flow diagram, piping and instrument diagram, mechanical layout and detail drawings, electrical drawings, instrument and control drawings, and construction specifications, including equipment specifications. MSE will also support the facility user for the technology transfer to the field. This will include providing advanced facility modification requirements, design progress reports, construction management services, and technical services during equipment commissioning.

\section{Technology NeEdS}

Thermal technologies are currently identified to play an important role in the treatment of many DOE waste streams. Emissions from these processes will be scrutinized by the public, regulators, and stakeholders. For some time, the public has been hesitant to accept thermal treatment of radioactive contaminated waste because of the emissions from these processes. While the technology for treatment of emissions from these processes is well established, it is not possible to provide the public complete assurance that the system will not allow any noncompliant emissions to exit the system.

Because of the possibility of noncompliant emissions and the public concern over thermal treatment systems, it has been decided that a controlled emissions off-gas system should be developed for implementation on DOE thermal treatment systems. While the conservation of mass precludes a completely closed cycle system, it is possible to apply the complete assurance concept to emissions.

\section{ACCOMPLISHMENTS}

The Controlled Emissions Off-Gas Demonstration was started in September 1994 when a limited group of persons with expertise in incineration systems, off-gas systems, plasma treatment systems, and instrumentation and a familiarity with the DOE mixed waste needs were assembled. The first phase was to identify technologies/systems that may have immediate possibility for implementation; this identification was required to establish the needs and design basis for the test bed. It was decided that standard off-gas treatment technology would be used on the front end of any system. Therefore, the focus was geared toward minimization of inputs, treatment, and monitoring and diversion methods to be employed at the back end of the emissions control system.

\section{Collaboration/TechNology Transfer}

The DOE Mixed Waste Focus Area, tasked MSE with establishing a controlled emissions off-gas test bed. The purpose of the test bed was to test and evaluate technologies/systems that may have applicability to the controlled emissions concept. An immediate goal of the test bed was to demonstrate a controlled emissions off-gas system that could be implemented in support of the Plasma Hearth Process Demonstration currently planned for the treatment of stored waste at INEL.

Collaborators on the project include Thermatrix, Inc., Pall, Inc., Marine Shale, Inc., SNL, DIAL, and SAIC.

For further information, please contact:

Grace Ordaz

Program Manager

U.S. Department of Energy

(301) $903-7440$

Julie Conner

Mixed Waste Focus Area Manager

U.S. Department of Energy

Idaho Operations Office

(208) 526-0648

Jeff Ruffner

Program Manager

MSE

(406) 494-7412 


\subsection{CORRELATION OF PLUTONIUM AND CERIUM VOLATILITY FOR BENCH-AND PILOT-SCALE PLASMA ARC CENTRIFUGAL TREATMENT SYSTEMS}

\section{TASK Description}

The plasma arc centrifugal treatment Contaminant Plumes Containment and Remediation Focus Area system is being considered by DOE, DoD, and EPA for treatment of numerous waste forms, including mine wastes, surplus pyrotechnic devices, waste sludges, and mixed and low-level radioactive wastes. In particular, one of the desired applications of the PACT system is to process soils and other wastes contaminated with low levels of plutonium. Because the PACT technology involves treating wastes at high temperatures, volatilization of metals, particularly plutonium, is a concern.

Since 1988, numerous tests of a pilot-scale (6-foot diameter) PACT system have been conducted at the DOE's WETO in Butte, Montana. For reasons of cost and safety, "hot" testing using plutonium was not considered for the pilot-scale facility; instead, cerium was used as a nonradioactive plutonium surrogate. While the use of cerium as a plutonium surrogate is well established, it is desirable to corroborate the results of the pilot-scale cerium tests with limited plutonium testing.

Independent of the pilot-scale cerium volatility tests, two series of small-scale PACT (1-foot diameter) volatility tests were conducted at other facilities. "Hot" tests using plutonium-spiked soil were conducted at INEL, and "cold" tests using cerium spiked soil were conducted at the Retech, Inc., facility in Ukiah, California.

The purpose of this task is to compare the cerium volatility results obtained with the pilot-scale PACT system to cerium and plutonium volatilities observed in the small-scale PACT experiments. The correlation between the small- and pilot-scale tests will be used to assess the applicability of the pilotscale system to the treatment of plutonium-contaminated soils, particularly those soils found at INEL's PIT-9. This task capitalizes, at relatively low cost, on data previously obtained under several different programs.

\section{Technology Needs}

PACT systems are being considered as a method for treating soils contaminated with low levels of plutonium. A comparison of existing results from pilotscale "cold" testing and small-scale "hot" testing is needed to assess the applicability of the pilot-scale system to treatment of plutonium-contaminated soils.

\section{Collaboration/TECHNOLOGY}

\section{Transfer}

The core technology of PACT systems is a rotating reaction chamber heated with a high-temperature plasma torch. Both the reaction chamber and the plasma torch are off-the-shelf technologies well established in the metallurgical industry. The pilotscale PACT system at WETO was provided in its original configuration by Retech, Inc. Since 1988, EPA, DOE, and DoD have sponsored demonstration tests of the pilot-scale PACT system. Anticipated applications of the PACT technology include processing surplus or out-of-date pyrotechnic devices, industrial sludges, and mixed and hazardous waste contaminated soils, including those found at INEL's PIT-9. 
For further information, please contact:

Jaffer Mohiuddin

Program Manager

U.S. Department of Energy

(301) 903-7965

\section{James Brown}

Landfill Stabilization Focus Area Manager

U.S. Department of Energy

Savannah River Operations Office

(803) 725-2760

\section{Jeff Ruffner}

Program Manager

MSE

(406) 494-7412 


\subsection{RADIOACTIVE SCRAP METAL RECYCLING}

\section{TASK DESCRIPTION}

This project is part of DOE-OST's Decontamination and Decommissioning program for recycling radioactive scrap metal (RSM), specifically radioactive scrap steels (RSS). Deactivation and decommissioning of DOE facilities will produce substantial volumes of RSS, which is currently buried in landfills. As burial costs are expected to rise sharply in the next few years, the purpose of the RSS Project is to demonstrate the economic viability of recycling this material into useful products.

The objective of this project is to design and construct a fully operational RSS recycling facility by 1999 at some non-WETO site. Figure 1.16 illustrates a potentially viable advanced design for a facility to produce carbon and stainless steel products from RSS. The RSS Project will take an integrated system approach to the design of an RSS recycle facility; this will greatly facilitate the design of an optimum full-scale RSS recycle facility. Design scope will include the ability to use carbon and stainless RSS feedstocks to produce high-quality slab, plate, sheet, or hot metal for reuse within Government and commercial nuclear facilities.
Several intermediate activities will be completed in the course of realizing the above objective. First, a feasibility analysis that identifies unit costs (dollars per ton) for a regional RSS recycling facility will be completed. Second, design steps, including conceptual, preliminary, and detail will then be completed. Finally, site selection, permitting and licensing, and RSS inventory within the DOE Complex will be completed. The current schedule calls for completion of the above activities early in midFY98, at which time construction will be possible.

Initial design strategy will closely parallel that of steel mini-mill operators. Thus, the RSS Project will focus initial investigative efforts on production techniques and equipment used in continuous melting/refining/casting/rolling operations to meet challenges associated with reprocessing RSS safely, efficiently, and economically.

\section{TeChNology NeEdS}

The technologies and operating practices used by steel mini-mill operators will likely need significant modification for use in RSS applications because

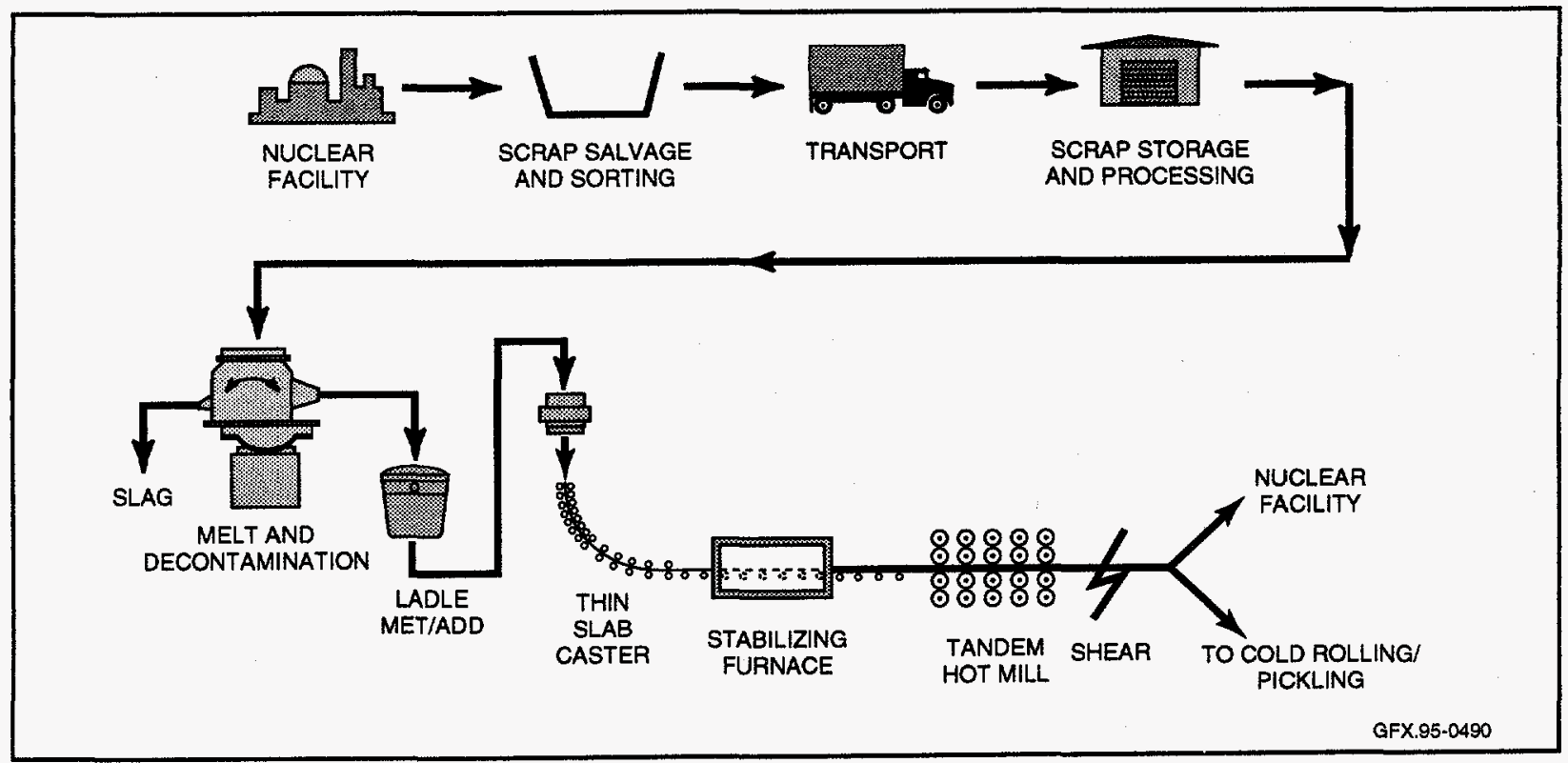

Figure 1.16. Process flow diagram for radioactive scrap metal recycling. 
standard steel production techniques do not have to deal with radioactive contaminants. Specific applications technologies identified include: radiological controls to comply with worker safety/exposure requirements, specialized processes to remove radioactive contaminants from the melt, and control of radionuclide emissions in air, water, and solid waste streams.

\section{ACCOMPLISHMENTS}

- The subcontract for the Regional RSS Recycle Facility Feasibility Analysis was initiated.

\section{COLLABORATION/TECHNOLOGY Transfer}

The RSS Project will collaborate with INEL as part of the Metal Recycle and Waste Minimization Program. The project team will seek industry partners with specific steelmaking expertise to join the effort; this will avoid duplication of effort and provide a means to dovetail commercial steelmaking expertise with on-going RSM Recycle Program efforts.

MSE will conduct the technology transfer program. Project documents will be disseminated to potential users within DOE, DoD, other federal agencies, state and local governments; and private industry.
This includes activities involving cooperative efforts with private industry as well as distribution of technical information through presentations and publications.

Existing forums will be used to facilitate technology transfer to the public and technical community. Presentations at workshops, conferences, symposia, seminars, and other formal meetings will serve this purpose.

For further information, please contact:

Stephen Lien

Program Manager

U.S. Department of Energy

(301) 903-7911

Robert Bedick

Facility Transition Focus Area Manager

U.S. Department of Energy

Morgantown Energy Technology Center

(304) $285-4505$

Jeff Ruffner

Program Manager

MSE

(406) 494-7412 


\section{RCRA METALS AND AIR STREAM CHARACTERIZATION PROJECT}

\section{TAsk Description}

The project goal will be to develop and provide a field test bed for evaluation of innovative and emerging technologies for screening of Resource Conservation and Recovery Act (RCRA) and other heavy metals in soils. The technologies will be selected from the OST-funded projects and respondents to a Commerce Business Daily (CDB) announcement.

Two sites have been selected for the demonstration. The primary site is located 3 miles west of Butte, Montana, near the town of Silver Bow, within and along the Silver Bow Creek streamside tailings corridor. The second site is located 3 miles east of Anaconda, Montana, in and along the Mill Creek drainage.

Field preparation and testing logistics will be provided for each site. MSE will characterize the sites using baseline technology for verification of the field methods. Performance specifications (i.e., limits of detection, accuracy, precision, and measurement ranges) for each heavy metal of interest will be defined. Field testing and evaluation of the selected technologies is scheduled for September 1995.

\section{ACCOMPLISHMENTS}

- The demonstration sites for the project were chosen.

- The site access agreements were prepared and signed.

- The Project Implementation Plan was prepared.

- The Category Exclusion and National Environmental Policy Act (NEPA) documentation was prepared and submitted.

- The test plan is being developed by EPA's Consortium for Site Characterization Technology (CSCT).
- The CBD announcement was issued.

- The Request for Proposal (RFP) was prepared.

\section{Technology NeEdS}

Current methods for determining heavy metal concentrations in soils are both costly and time consuming. The development of this technology should enable field analyses to be performed immediately on site, with a sensitivity that meets RCRA limitations.

MSE's function in this project is to select a test bed and verify field analyses performed by field detection technologies that can identify and quantify RCRA metals contained in soils.

\section{Collaboration/TechNology Transfer}

MSE personnel are working in conjunction with DOE's Characterization, Monitoring, and Sensor Technology Crosscutting Program (CMST-CP) technical support team at Ames Laboratory and with the EPA's CSCT. MSE will choose technologies, select a test, prepare a test bed, and conduct confirmatory laboratory analysis to verify test results of the field analytical technologies selected for demonstration. MSE will fund a portion of the mobilization, the technology demonstration, and demobilization for a 5-day period for each chosen technology. The demonstrations will be performed in accordance with CSCT's Guidance Manual for the Preparation of Site Characterization Technology Demonstration Plan.

Potential users of the technologies are widespread across the DOE Complex and the United States. Because the need is extensive, the technologies would be readily transferable to private entities that must evaluate the extent of RCRA metals at contaminated sites outside DOE. Some candidates for field 
detection technologies are Superfund sites, existing mining operations, and terminated mining operations.

Developments from the evaluations will result in dissemination of technical and economic information through presentations and/or publications at national meetings, conferences, workshops, seminars, etc.

For further information, please contact:

Caroline Purdy

Program Manager

U.S. Department of Energy

(301) $903-7672$

Paul Wang

Field Project Manager

U.S. Department of Energy

Ames Laboratory

(515) 294-6773

Creighton Barry

Program Manager

MSE

(406) 494-7268 


\subsection{DEPARTMENT OF ENERGY/U.S. AIR FORCE MEMORANDUM OF UNDERSTANDING}

The Department of Energy/U.S. Air Force Memorandum of Understanding (DOE/USAF MOU) Program was formed to jointly reduce waste generation in common areas and avoid duplication of research efforts. The program promotes the development of pollution prevention technologies, such as material substitution and advanced manufacturing techniques, to reduce or eliminate the generation of hazardous waste. Joint agency development permits leveraging of federal funds.

The DOE/USAF MOU will cover all phases involved in industrial processes as shown in Figure 1.18. It will help expedite future selection and implementation of the best technologies and show immediate and long-term effectiveness for DOE and USAF sites. The program will conduct performance comparisons of available technologies under field conditions based on effectiveness with respect to the technology itself, risk reduction, and general acceptability.

Several projects have contributed to the establishment of a formal program between DOE and the USAF. Since the early 1980s, the Air Force
Civil Engineering Support Agency (AFCESA), formerly the Air Force Engineering Services Center (AFESC), requested that INEL perform a variety of environmental projects. These included:

- Sodium Sulfide/Ferrous Sulfate Metals Precipi- tation;

- Metals Recovery from Sludge;

- Bicarbonate of Soda Stripping;

- Noncyanide Metal Strippers; and

- Biodegradable Solvent Substitution.

In 1988, a MOU was signed between EM and the Laboratory Commander of the AFESC. This MOU stated that the two organizations would jointly develop mutually beneficial environmental technologies, promote technology information exchange, and assist in arranging interlaboratory/industry partnerships.

FY92 was the first year for the formal program. The projects emphasize pollution prevention by address-

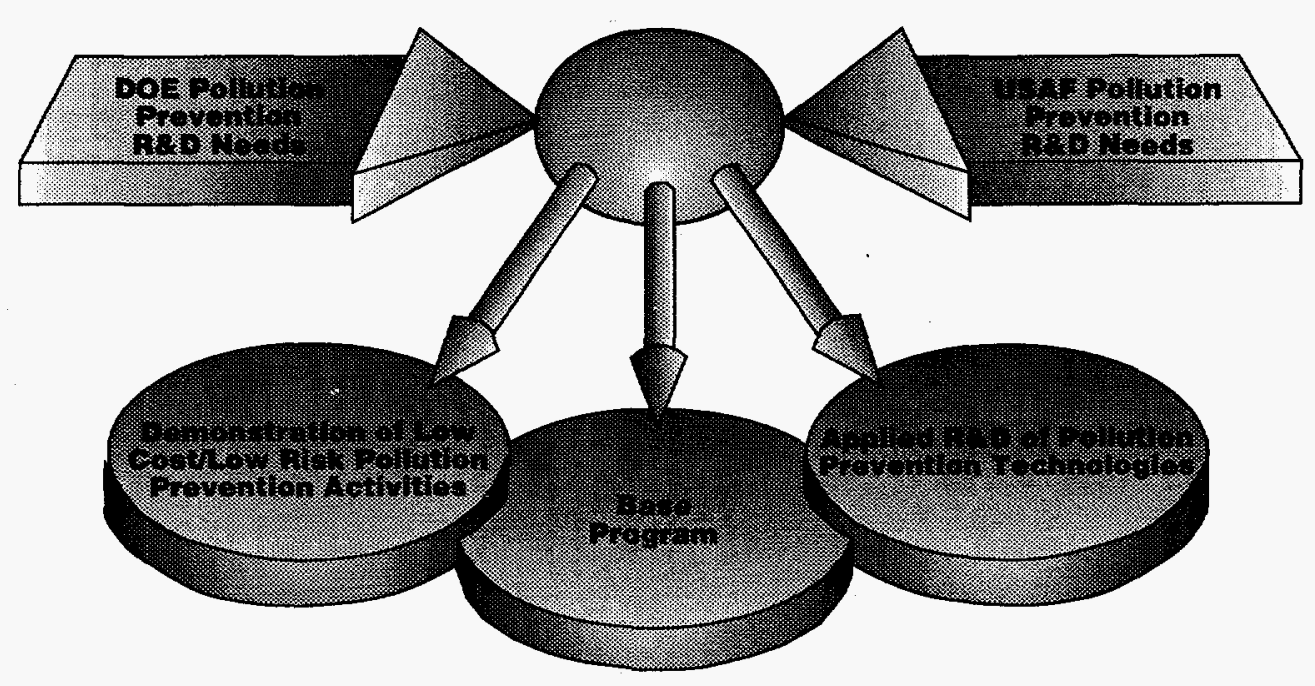

GFX.95-0483

Figure 1.18. The industrial processes of the DOE/USAF MOU Program. 
ing wastes regulated by RCRA, the Clean Air Act (CAA), and the Clean Water Act (CWA). The Spray Casting Project, conducted by MSE, Inc., is a major component activity of the DOE/USAF MOU. This project is described in greater detail in Section 1.19 of this publication.

For further information, please contact:

\section{Miles Dionisio}

Program Manager

U.S. Department of Energy

(301) 903-7639

\section{Captain William Gooden}

Project Manager

AL/EQS-OL

(904) 283-6239 


\subsection{SPRAY CASTING PROJECT}

\section{TASK DESCRIPTION}

This task is developing a new thermal spray process that can be used to 1) apply coatings that will replace hard chromium electroplating or 2) perform near-net shape fabrication of difficult to fabricate materials, such as special nuclear materials. The new process is the pressure-controlled atomization process (PCAP), which was developed by and has dual application for both DOE and the USAF. A schematic of PCAP is shown in Figure 1.19.

OST supports waste minimization efforts within DOE's Defense Programs. Despite a dramatic decrease in production requirements at Defense Programs' facilities, manufacturing needs still exist. One such manufacturing need is for the fabrication of waste transportation and storage casks from depleted uranium, and PCAP is supporting this effort. Compared to existing fabrication techniques, the near-net shape thermal spray fabrication of casks will result in reduced amounts of waste being generated, and in addition, manufacturing costs will also be reduced.

The USAF effort is directed at replacing hard chromium electroplating as a repair technique on aviation parts. The chromium-plating process will be replaced by a thermally sprayed coating of equal or superior properties. The USAF portion of this project will be demonstrated at the National Defense Center for Environmental Excellence (NDCEE) in Johnstown, Pennsylvania, where an engineering demonstration PCAP unit will be designed, fabricated, and installed.
The USAF portion of this project is supported by the Environics Directorate of the Armstrong Laboratory, Tyndall Air Force Base, Florida.

\section{Technology NeEdS}

The spray casting technology will avoid or eliminate waste as a result of material or process changes from existing methods, and will reduce the generation of waste material at the source. Spray casting, either as a coating or for producing near-net shape parts, would be of significant value to the DOE Complex. The USAF has a basic need to replace chromium electroplating as a means of repair/refurbishment of aviation parts because hexavalent chromium, a byproduct of the plating operation, is a well-known carcinogen, and its safe disposal is difficult and expensive. Spray casting of thin, well-adhering, hard metallic coatings onto parts can provide a replacement process for the chromium electroplating. This requirement is directed by RCRA relative to disposal requirements for listed waste streams. Five USAF Logistics and Service Centers generate approximately 1,000 gallons of hazardous chro-

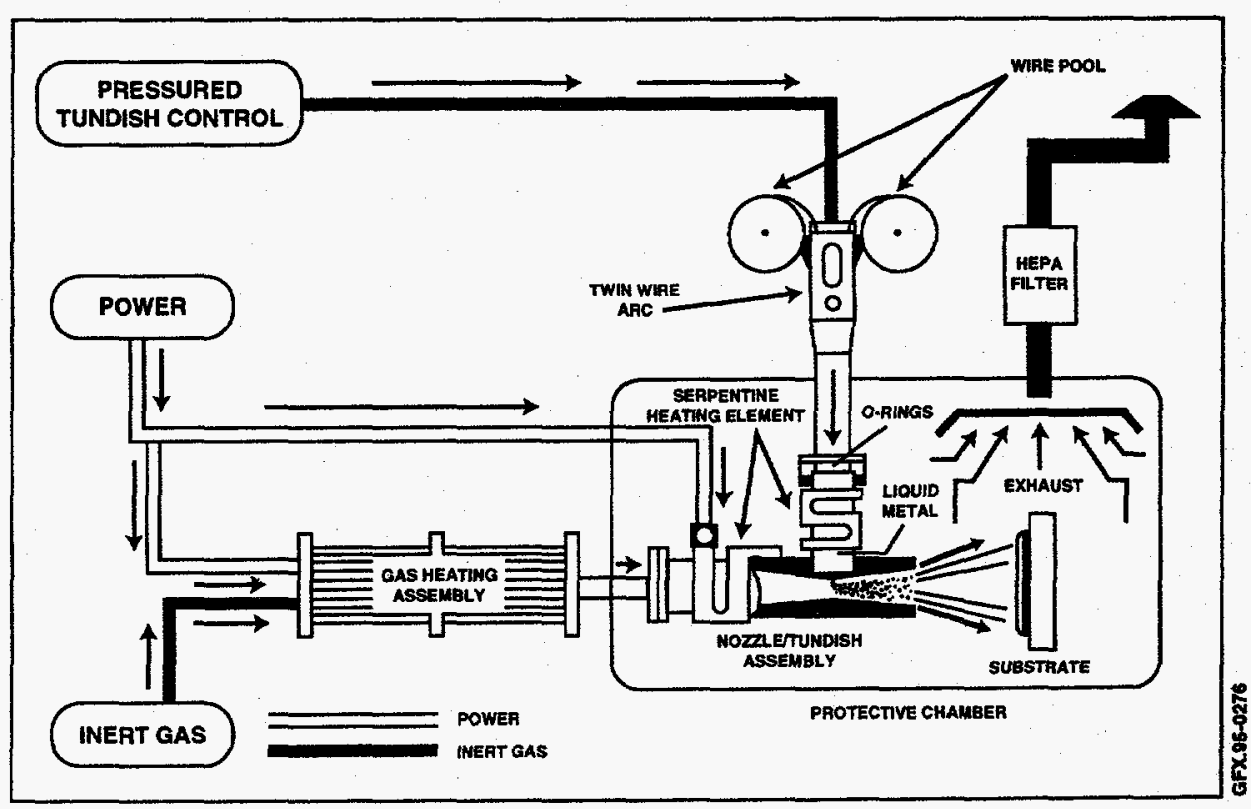

Figure 1.19. Pressure-controlled atomization process. 
mium-plating waste per week. Disposal costs are $\$ 2-3$ million per year.

\section{ACCOMPLISHMENTS}

- Completed the USAF Final Report, which contains the MSE Test Series, Boeing Test Series, Wright Laboratory Test Series, and the Wear and Corrosion Integrated Test Series reports.

- In support of radioactive waste transportation and storage caskets, fabricated a circular cylinder that is 3 inches in diameter, 4 inches long, and one-quarter inch thick with stepped lap joints on the ends, that will allow cylinder stacking.

- Initiated design and fabrication of an engineering demonstration PCAP unit for NDCEE.

- Completed the conceptual design for a DOE PCAP system to be installed at Oak Ridge $\mathrm{Na}$ tional Laboratory (ORNL).

\section{Collaboration/Technology Transfer}

The spray casting process will be transferred to DOE Defense Program Manufacturing facilities once the technology is demonstrated. The project is being developed in collaboration with MSE, DoD, and ORNL. Boeing and Wright-Patterson AFB have been involved in a test series conducted to provide an engineering evaluation of the spray process for the Air Force portion of the project. Tests including chemistry, metallurgy, internal stress measurement, hardness, corrosion resistance, abrasion resistance, and adhesion strength of the sprayed coating have been performed.

For further information, please contact:

Miles Dionisio

Program Manager

U.S. Department of Energy

(301) 903-7639

Captain William Gooden

Project Manager (Air Force)

AL/EQS-OL

(904) 283-6239
Allan Miller
Program Manager
MSE
(406) 494-7319 
WORK FOR OTHERS

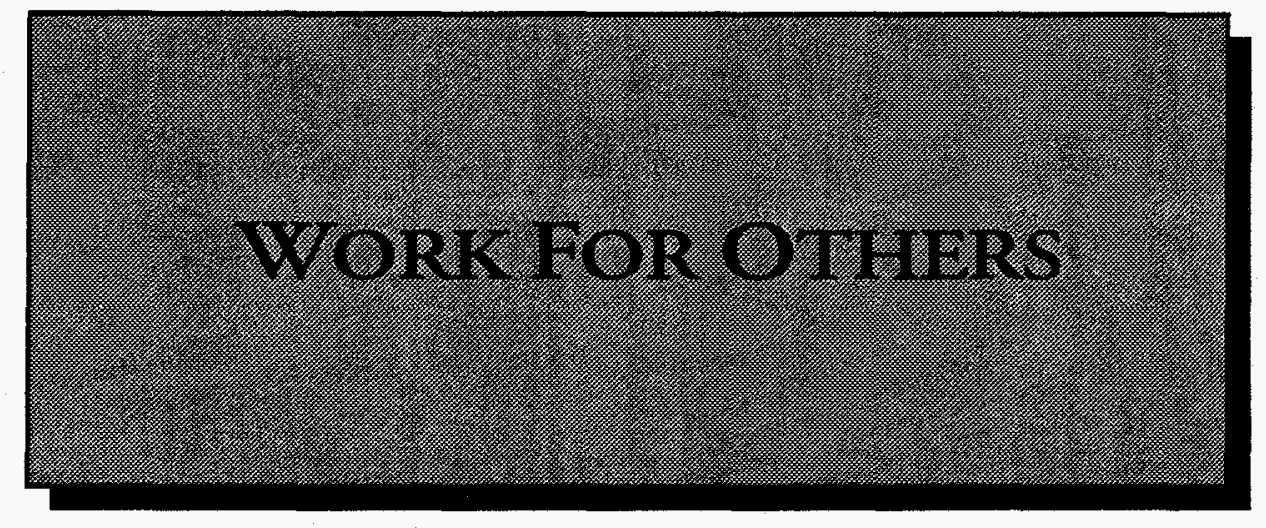

Section 2.0 


\section{1 \\ U.S. ARMY CONSTRUCTION ENGINEERING RESEARCH LABORATORY PROJECTS}

\section{CONSTRUCTION ENGINEERING RESEARCH LABORATORY (CERL) Plasma/Pyrotechnic Ordnance Plasma Demonstration}

\section{TAsK Description}

DOE is assisting the U.S. Army and U.S. Army Corps of Engineers with its need to dispose of hazardous waste within the DoD Complex using safe, environmentally acceptable methods. WETO testing determined the feasibility of using plasma arc technology to treat hazardous waste and to minimize or eliminate resulting hazardous waste forms with the successful treatment testing of pyrotechnic munitions proximity fuzes in the Plasma Arc Centrifugal Treatment (PACT-6) system during FY91 and FY92.

The focus of the current program is to complete the following tasks in support of testing and future system development and operational optimization.

- Upgrade the pilot-scale PACT-6 system, including integrated controls, off-gas, secondary combustor, and DC power supply upgrade.

- Complete slag optimization conditioning studies and perform a PACT- 6 mass and energy balance.

- Design, fabricate, install, and commission the small-scale plasma furnace (SSPF). This equipment will be used to economically screen candidate waste mixtures prior to running on the PACT -6 plasma unit.

- Procure and install a bench-scale slag melter. This unit will also be used as a screening device to economically test waste mixtures prior to testing on the SSPF or PACT -6 units.

- Complete and issue test reports on the PACT-6 equipment upgrade shakedown tests, the high metals test, and extended operational test and perform additional screening tests on contami- nated Rocky Flats soils and simulated U.S. Navy shipboard municipal waste.

- Work with private-sector torch developers to develop, build, and test a hybrid torch capable of working in both the transferred and non-transferred modes.

\section{Technology NeEdS}

The U.S. Army and the Army Corps of Engineers currently have numerous pyrotechnic ordnances and fuze devices stockpiled that require disposal and contaminated soils at various sites that require treatment. The U.S. Navy has shipboard wastes that may be treated by the plasma process, and CERL is considering some initial feasibility tests on this type of waste.

\section{ACCOMPLISHMENTS}

WETO testing has determined the feasibility of using plasma arc technology to treat hazardous waste and to minimize or eliminate resulting process hazardous waste forms. This was accomplished through the successful testing of pyrotechnic munitions and fuzes in the PACT-6 system during FY91 and FY92. Much of the work described in the above tasks has been completed, and the equipment modifications are currently underway. In addition, the following have also been successfully completed:

- the shakedown, high metals, and operability duration tests;

- the SSPF and bench-scale melter commissioning; and

- the slag studies and mass and energy balance tasks.

This work will directly support ongoing testing and future system development and operational optimization. 


\section{Collaboration/Technology}

\section{Transfer}

The PACT -6 was purchased from Retech, Inc., and initially demonstrated by DOE and EPA under the SITE Program.

\section{CERL Heavy Metals REMEDIATION}

\section{TASK DEsCription}

MSE is performing a series of waste minimization and environmental restoration projects at the Watervliet Arsenal (WVA) in Watervliet, New York. A component of the U.S. Army Materiel Command, the WVA consists of 1.2 million square feet of manufacturing floor space. WVA produces cannons and other products serving DoD and allied countries.

The WVA projects, funded by the DoD through the Environmental Engineering Division, U.S. Army CERL, are designed to demonstrate and evaluate non-plasma technologies and their effectiveness to treat DoD and DOE waste forms. The overall intent of this program will be to leverage both $\mathrm{DoD}$ and DOE resources to develop and demonstrate viable treatment technologies to solve some specific environmental problems. WETO and CERL staff work together by combining resources in an attempt to find viable treatment alternatives for various waste streams.

The following projects have been completed or are in progress at WVA.

\section{Treatment of Manufacturing Operation Oil Waste}

The goal of this project is to develop a metalworking fluid management program for WVA manufacturing operations. MSE is providing engineering services, construction oversight, and technology testing services for selecting, designing, and testing of a full-scale unit that will address fluid management and waste minimization concerns of the metalworking fluids for the Flexible Manufacturing
System at WVA. Once a fluid management process has been proven to work satisfactorily at the Flexible Manufacturing System, similar systems will eventually be installed in other manufacturing areas at the arsenal.

Treatment of Chromium VI Wastestreams using Sulfate-Reducing Bacteria

The acid waste stream produced at WVA contains a significant concentration (29 milligrams per liter on the average) of hexavalent chromium (Cr VI). Because $\mathrm{Cr}$ VI is a highly mobile and carcinogenic substance, reduction of the $\mathrm{Cr}$ VI to chromium III (Cr III), a much less toxic substance, is desirable.

The goal of this project is to demonstrate a pilotscale continuous bioreactor using sulfate-reducing bacteria to treat chromium VI-contaminated waste water from WVA's chrome-plating facilities. MSE engineers are designing, constructing, and evaluating a bioreactor to achieve this goal.

Instrument and Process Control Upgrade of the Industrial Waste Treatment Plant

For this project, MSE is providing process engineering expertise to help with modernizing the industrial waste treatment plant at WVA. MSE's instrumentation and control engineers are assisting in designing and installing state-of-the-art technologies and controls on two acid wastestreams.

Chrome-Plating Facility Environmental Technology

The goal of this project is to design, demonstrate, and install a pilot-scale rinse water recovery system at one of WVA's chromium-plating facilities. MSE is providing engineering services, construction oversight, project management, and technology testing services to test and demonstrate an innovative technology that will remove chromium from the plating rinse water and then recycle the rinse water that is currently sent to an industrial water treatment facility. Treating and recycling the rinse water will reduce volume and makeup water requirements, resulting in potential cost savings for the WVA's plating operations. 


\section{Waste Acid Detoxification and Reclamation}

The goal of this project is to evaluate the effectiveness of a waste acid recovery system, which is supplied by Viatech and provided by Pacific Northwest Laboratory (PNL) to the WVA. The system will be tested on the sulfuric/phosphoric acid used in the chrome-plating facility. MSE will support installation and evaluation of the technology, which will be installed in the 120 Chrome-Plating Area at WVA.

\section{Heavy Metals in Soils and Plume}

This task includes identifying and characterizing contamination sources and determining the specific contaminants and the extent of the contamination if it exists. MSE will perform a site characterization and recommend technologies for the specific remediation situations. MSE will also ensure the site cleanup is complete, using the best appropriate technologies.

\section{Hazardous Air Pollution Demonstration}

The goal of this project is to demonstrate a closed loop fume eliminator technology to be used for chromium emissions reduction. MSE is providing engineering services, construction oversight, project management, and technology testing services for selecting, designing, and testing the pilot-scale demonstration unit supplied by Castle Hone, Inc.

\section{Underground Storage Tank Monitoring Up- grade}

This project involved providing engineering and installation services to link existing underground storage tank fluid level indicators and leak detection monitoring equipment to the WVA computer network. This project allows for remote monitoring of fluid level and leak detection information through the computer network to designated monitoring personnel and emergency response locations at WVA.

\section{Technology Needs}

The projects at WVA are designed to demonstrate and evaluate technologies and their effectiveness to treat DoD and DOE waste forms. The overall intent of the program is to share DoD and DOE resources in an effort to develop and demonstrate viable treatment technologies to solve specific environmental problems. MSE and CERL will work together to find viable treatment alternatives for various waste streams.

\section{ACCOMPlishments}

Treatment of Manufacturing Operation Oil Waste

- The work plan was written and approved.

- The metalworking fluid (coolant) recycling technology was selected and was installed in June of 1995.

- A subcontract to install a reverse osmosis unit was issued; the unit was installed in May of 1995.

- A Request for Proposal for an oil/water separation technology was issued; review and selection of the separation technology occurred in June of 1995.

Treatment of Chromium VI Wastestreams using Sulfate-Reducing Bacteria

- A Categorical Exclusion for the project demonstration at WETO was granted by the Pittsburgh Energy Technology Center (PETC), which fulfills the requirements of the National Environmental Policy Act.

- An experimental design for the laboratory testing at WETO was developed.

- Laboratory equipment to support the project was installed at WETO.

Instrument and Process Control Upgrade of the Industrial Waste Treatment Plant

- The estimate to complete the controls upgrade was completed.

- The preliminary piping and instrumentation drawings were completed. 
Chrome-Plating Facility Environmental Technology

\section{Rinse Water Recycle Demonstration}

- Proposals were received from Norchem International, Inc., and Zenon Environmental, Inc. Norchem is a distributor for the patented RETEC Chrome Recovery System (CRS), and Zenon is supplying their patented microfiltration technology for separating tramp metal sludges precipitated from CRS.

\section{Chrome-Plating Bath Purification}

- An electrolytic process developed by the U.S. Bureau of Mines at the Rolla Research Center will be installed to remove contaminants from the plating bath. An agreement was sent to the U.S. Bureau of Mines to outline the scope of work and to formalize tasks for the Bureau's $\$ 100,000$ in-kind contribution.

\section{Waste Acid Detoxification and Reclamation}

- PNL/Viatech has been contacted to obtain system configuration information in preparation for developing installation and test plans. WVA is preparing documentation to transfer funds to PNL for their equipment.

\section{Heavy Metals in Soils and Plume}

- Funding for this project has not yet been received.

\section{Hazardous Air Pollution Demonstration}

- Castle Hone, Inc., was contacted regarding their proprietary closed loop fume eliminator technology that was selected by WVA to be tested for its effectiveness in reducing chromium emissions.

\section{Underground Storage Tank Monitoring Up-} grade

- Interface electronics boxes were installed and tested at eight underground storage tanks to provide automatic tank level/leak detector information to the WVA computer network. Four additional interface boxes were fabricated for future installation.

For further information, please contact:

Plasma/Pyrotechnic

Hany Zaghloul

Program Manager

U.S. Army CERL

(217) $373-3486$

John Wengle

U.S. Department of Energy

(301) $903-8490$

Jeff Ruffner

Program Manager

MSE

(406) 494-7412

\section{CERL Heavy Metals Remediation}

Hany Zaghloul

Program Manager

U.S. Army CERL

(217) $373-3486$

John Wengle

U.S. Department of Energy

(301) 903-8490

Creighton Barry

Program Manager

MSE

(406) 494-7268 


\section{2 \\ ARMY AMMUNITION RESEARCH DEVELOPMENT ENGINEERING CENTER PROJECT}

\section{TASK DEscription}

The U.S. Army and U.S. Navy have numerous pyrotechnic ord nance stockpiled for disposal. This task involves the development of the Plasma Arc Centrifugal Treatment (PACT) process and associated equipment to support full-scale implementation of the technology for the disposal of pyrotechnic ordnance devices. Specific development tasks include development of systems for the handling and feeding of ordnance, modifications to system offgas configuration to minimize plugging and ensure proper destruction of organic compounds, and studies of slag conditioning to enhance system operability and minimize waste volume. The final deliverable for this effort will be the conceptual design and engineering specification for a plasma arc system for ordnance destruction.

\section{ACCOMPLISHMENTS}

Previous projects for the U.S. Army Ammunition Research Development Engineering Center (ARDEC) have demonstrated the ability of the plasma arc centrifugal treatment technology to process pyrotechnic ordnance. Under the current project, studies are being conducted to identify a system configuration best suited to projected U.S. Army needs. Specific areas under evaluation are torch type and size, off-gas system configuration, and feed-handling systems. Additional studies are being conducted to estimate waste loading and molten pool fluxing requirements. Data from the slag study will be used in small- and full-scale plasma arc testing.

\section{TeChNOLOGy NeEDS}

Increasing environmental restrictions are making open burning/open detonation of ordnance an unacceptable method of disposal. Previous screening tests have shown that plasma technology has the ability to process representative ordnance into an environmentally benign waste form.

Attempts to process ordnance in conventional incinerators have been unsuccessful for representative ordnance types. Munitions containing smokes and dyes can overload pollution abatement equipment, while flare and illumination devices can produce high localized temperatures that damage incinerator combustion chambers. In addition, a number of devices contain electronic components or general configurations that remain classified. Conventional incinerators may not guarantee physical destruction satisfactorily to address these issues. Application of the PACT system to the disposal of stockpiled ordnance and fuze devices has the potential to satisfy environmental and security issues.

\section{Collaboration/Technology Transfer}

This technology was originally developed by Retech, Inc., and initially demonstrated by DOE. Under an agreement with DOE, the U.S. Army is currently using the equipment installed at WETO to develop the process for application to pyrotechnic ordnance. There are currently no industrial partners involved in this task. 
For further information, please contact:

Larry Weiner

Program Manager

ARDEC

(201) 724-2138

John Wengle

U.S. Department of Energy

(301) $903-8490$

Jeff Ruffner

Program Manager

MSE

(406) 494-7412 


\subsection{MINE WASTE TECHNOLOGY PROGRAM}

\section{TASK DesCription}

Mining waste generated by active and inactive mining production facilities and its impact on human health and the environment is a growing concern for government entities, private industry, and the general public. The mission of the Mine Waste Technology Program (MWTP) is to advance the understanding, development, and application of engineering solutions to national environmental issues resulting from the past practices of mining, milling, leaching, and smelting of metallic ores. See Figures $2.3 \mathrm{a}, \mathrm{b}$, and c. To accomplish this mission, the MWTP has identified the following activities:

- identify and prioritize mining waste issues;

- develop a quality assurance plan for the program as a whole;

- conduct large pilot- and field-scale demonstrations of promising technologies;

- conduct bench-and small-scale research on promising technologies;

- perform technology transfer of information gathered during the pilot program; and

- establish training and educational programs directed toward personnel in mine waste treatment.

\section{ACCOMPLISHMENTS}

To date, the MWTP has developed five documents under Activity 1 that relate to specific mine waste issues. The quality assurance plan for the program as a whole has been completed and implemented under Activity 2. Five field-scale demonstrations under Activity 3 have been approved by the management committee (see Section 2.2). Field construction activities are completed on two of these technologies with testing ongoing. A third technology is scheduled for a second phase of field construction. Five bench-scale research projects have been developed and are currently operating under
Activity 4. The final report on the first of these projects was completed within the first portion of FY95. The projects under Activity 5 have consisted of a number of sponsored seminars, workshops, symposiums, and annual report publications. Activity 6 has established a graduate emphasis program at Montana Tech of the University of Montana (Montana Tech) that currently has more than 20 students enrolled. This activity has also sponsored a number of educational activities for grade school, middle school, and high school students.

\section{TeChNOLOGY NeEDS}

Mine wastes from inactive and abandoned mines are a major environmental liability for federal, state, and local government entities, and private business. No viable technology is available to address many of the waste forms generated by these mining sites. Numerous problems arise from the long-term, cradle-to-grave nature of these waste forms. Specific

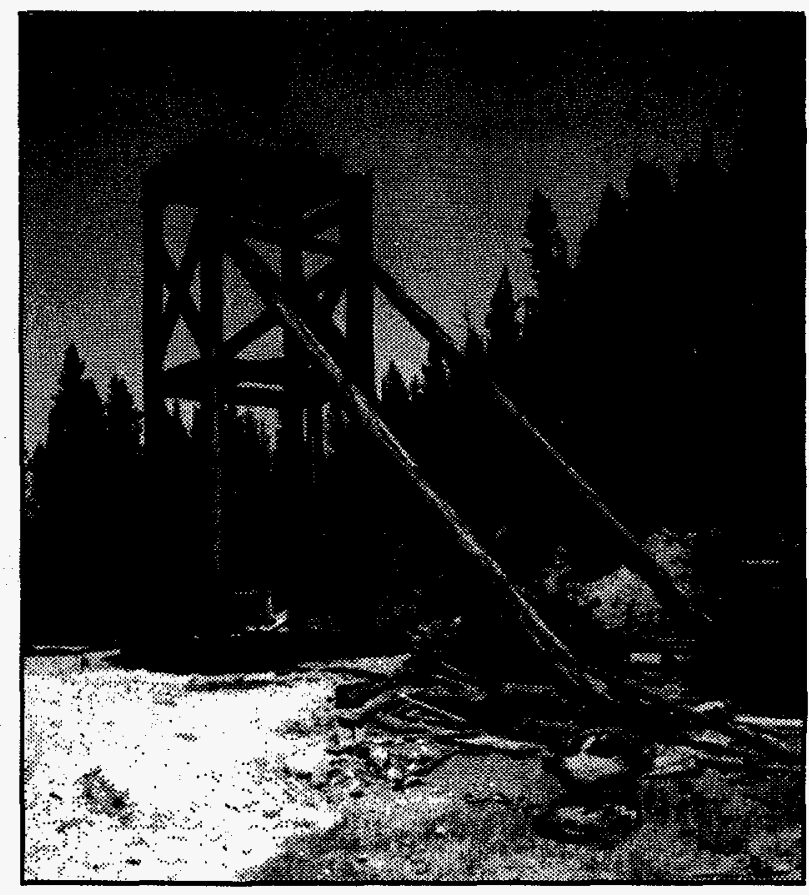

Figure $2.3 \mathrm{a}$. Headframe of mine shaft and waste piles at the Lilly/Orphan Boy Mine, site of the SRB Demonstration Project of the MWTP. 


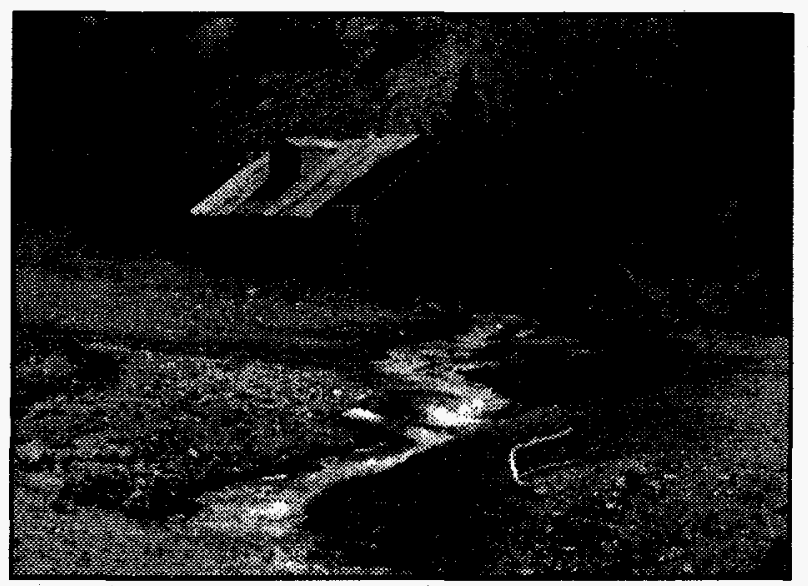

Figure 2.3b. The Mike Horse Mine adit, site of the Clay-Based Grouting Demonstration Project of the MWTP.

problems that have been identified deal with the control and mitigation of acid generation, the mobility of toxic constituents generated by mining activities in both water and air, and the recovery of resources from wastes. A number of conventional technologies are in use at mining sites, but for the most part, the use of these technologies is viewed as interim, stop-gap measures until actual controls or solutions are developed.

\section{COLlaboration/TEChNOLOGY TrANSFER}

tana Gold Properties Inc., FMC Corporation, TVX Mining, Inc., the Western Governors' Association, and the EPA SITE Program. Activity 5 processes have involved direct collaboration with many of the previously mentioned organizations in addition to Placer Dome Mining, Inc., and Pegasus Mining, Inc. Collaboration within Activity 6 has involved Montana Tech, Montana State University, the University of New Mexico, Kansas State University, the University of Nevada at Reno, the University of Utah, as well as several local school districts.

\section{For further information, please contact:}

\section{Roger Wilmoth}

Program Manager

U.S. Environmental Protection Agency

(513) $569-7509$

\section{John Wengle}

U.S. Department of Energy

(301) 903-8490

\section{Creighton Barry}

Program Manager

MSE

(406) 494-7502

The MWTP is jointly administered by EPA and DOE. The program also has an oversight committee that consists of individuals from EPA, DOE, U.S. Bureau of Mines, the U.S. Forest Service, the U.S. Bureau of Land Management, the Western Governors' Association, the State of Idaho, the State of Montana, and the Northern Plains Resource Council. The program is in direct collaboration on projects within Activities 3 and 4 with the U.S. Bureau of Mines, Montana Tech, the Center for Biofilm Engineering, Noranda Mining Corporation, ASARCO, Inc., ARCO, Inc., Mon-

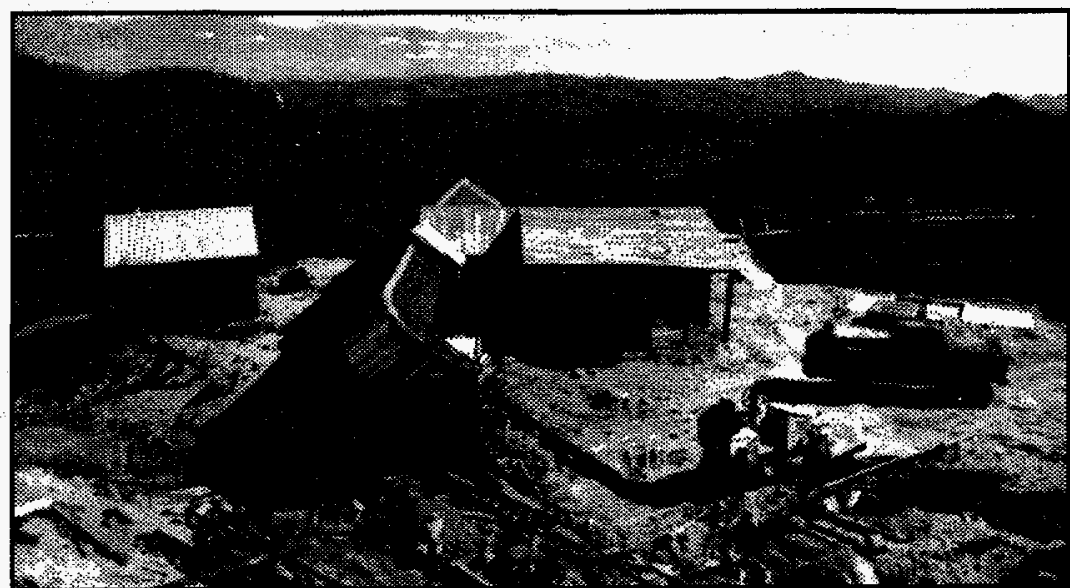

Figure 2.3c. The Crystal Mine Complex, site of the Remote Mine Site Demonstration Project of the MWTP. 


\section{4 \\ MINE WASTE TECHNOLOGY PROGRAM \\ ACTIVITY III PROJECTS}

Acid mine drainage forms when normally clean water comes in contact with metal sulfide minerals in the presence of air. The valuable minerals that are exploited by mining activities are metal sulfides.

Personnel from EPA's Region 8 have identified several hundred mine sites where acid mine drainage emanates from point sources and drains directly into surface waters. The environmental damage caused by these acidic, metal-laden waters can be severe to aquatic organisms. Hundreds of miles of surface water courses are affected by these drainages in the western United States.

The first three demonstrations of Activity III of the MWTP all relate to the prevention and/or control of acid mine drainage.

\section{Project 1 - Remote Mine Site Demonstration Project}

The purpose of Activity III, Project 1 is to develop a water-treatment process facility at a remote mine site that is capable of treating a flow of acidic, metal-laden water. The process facility should be self-regulating for variable flow rates and capable of operating without the addition of external power and without operator assistance for extended periods of time in harsh conditions (4-5 months). The site chosen for this project is the Crystal Mine, a remote, inactive mine site located 7 miles north of the community of Basin, Montana, immediately adjacent to Uncle Sam Creek. Between 20 and 50 gallons per minute (gpm) of acidic, metal-laden water drains from the lower portal of the mine workings directly into Uncle Sam Creek.

Bench-scale testing of the process chemistry was completed in FY94, all the legal and environmental permits needed to construct the field-scale unit have been acquired, the field-scale process train has been designed and reviewed, and finally, a water treatment facility consisting of six stages has been constructed at the Crystal Mine. The six stages of the facility are initial oxidation, alkaline reagent addi- tion, final oxidation, initial solid-liquid separation, neutralization ( $\mathrm{pH}$ adjustment), and final solid-liquid separation. Operation and testing of this facility began on August 26, 1994.

\section{Project 2 - Clay-Based Grouting Demonstra- tion Project}

The purpose of Activity III, Project 2 is to produce a subsurface barrier formed of clay grout that will prevent clean water from coming in contact with sulfide minerals contained within the mineralized portion of an abandoned mine. This barrier will thus prevent the formation of acid mine drainage. The site chosen for this project is the Mike Horse Mine, a remote, inactive mine site located 12 miles east of the community of Lincoln, Montana, immediately adjacent to Mike Horse Creek. Between 50 and $100 \mathrm{gpm}$ of acidic, metal-laden water drains from the 300-foot-level portal of the mine workings directly into Mike Horse Creek, which is one of the creeks that form the Blackfoot River.

All the legal and environmental permits needed to place the grout in the subsurface have been acquired. The geology, geochemistry, and hydrology of the mine site were characterized during FY93-94. Working agreements with the mine owners and the Ukrainian corporation that developed the clay grouting formulation to be used in the demonstration have been acquired, and the field-scale application of this technology took place early in FY95. Final reports for this project are due in mid-year 1996. Testing of this application began immediately after emplacement and will continue through the fall of 1995.

\section{Project 3 - Sulfate-Reducing Bacteria Demon- stration Project}

The purpose of Activity III, Project 3 is to demonstrate the use of sulfate-reducing bacteria (SRB) for the treatment of acid mine drainage. The bacteria will be used in an innovative application by placing an organic substrate containing the bacteria within 
the subsurface mine workings of the chosen site; these bacteria have been shown to metabolically produce hydrogen sulfide and alkalinity from sulfate that is dissolved in water. Acid mine drainage contains sizeable quantities of dissolved sulfate in addition to acid and metals. The hydrogen sulfide produced by the SRBs will react with the metals in the acid mine drainage to produce solid metal sulfides that will precipitate out of solution. The alkalinity, which is also produced by the bacterial action, will serve to neutralize the acidic component of the drainage. The site chosen for this project is the Lilly/Orphan Boy Mine, a remote, inactive mine site located 10 miles south of the community of Elliston, Montana, immediately adjacent to Telegraph Creek. Between 3 and $5 \mathrm{gpm}$ of acidic, metal-laden water drains from a collapsed portal of the mine workings directly into Telegraph Creek.

All the legal and environmental permits needed to conduct the demonstration and a working agreement with the mine owner has been acquired. The organic substrate was placed into the mine workings on August 29 and 30, 1994. Testing of this technology application began immediately after this placement.

\section{Project 4 - Nitrate Removal Demonstration Project}

The purpose of Activity III, Project $\mathbf{4}$ is to demonstrate a number of technologies to remove nitrate from mine water and destroy the nitrate by producing nitrogen gas. Nitrate is found in mine water as a result of a number of mining processes, including blasting with nitrate-based blasting agents, destruction of cyanide used in leaching precious metals from rocks, and fertilization during reclamation of ground disturbed by mining activities.

Excess nitrate in water is considered to be an environmental pollutant due to the propensity of nitrate to increase the biological activity in water. Such increases in biological activity can cause algal blooms, an increase in biological oxygen demand, and eutrophication. The technologies that will be tested are ion-exchange, electrochemical ion-exchange, and biological denitrification. The site chosen for this project is the Mineral Hill Mine, an operating mine located near the community of Gardner, Montana.
Approximately $10 \mathrm{gpm}$ of nitrate-enriched water is discharged from the 600-foot-level portal of the mine into the tailings pond of the operation.

\section{Project 5 - Biocyanide Demonstration Project}

The purpose of Activity III, Project 5 is to demonstrate the use of bacteria to destroy the cyanide found in mine wastes that result from using this chemical for leaching precious metals from ores. Residual cyanide in these wastes is a strong hazard to the environment; cyanide is a specific poison to many life forms, including humans. Cyanide also has the ability to complex with many substances, specifically metals, and strongly increase the solubility and therefore the mobility of those substances.

This project will test two biological methods of destroying cyanide in mine wastes. The first of these technologies is a bacteria known as $P_{\text {seudomo- }}$ nas putida. This bacteria has been isolated by researchers from the Center for Biofilm Engineering at Montana State University and Selma University in Alabama. The second technology that will be tested is the use of indigenous bacteria that also show the ability to destroy cyanide. These two technologies will be tested against each other side-by-side to determine which process is best used to destroy residual cyanide in a spent heap from a heap leaching mine operation.

As of yet, no site has been chosen for this project.

For further information, please contact:

Roger Wilmoth

Program Manager

U.S. Environmental Protection Agency

(513) 569-7509

John Wengle

U.S. Department of Energy

(301) $903-8490$

Creighton Barry

Program Manager

MSE

(406) 494-7502 


\section{5 \\ NATIONAL AERONAUTICS AND SPACE ADMINISTRATION (NASA)/U.S. DEPARTMENT OF ENERGY (DOE) MAGNETOHYDRODYNAMIC ACCELERATOR RESEARCH INTO ADVANCED HYPERSONICS (MARIAH) PROJECT}

\section{TASK DESCRIPTION}

The goal of this project is to evaluate and develop magnetohydrodynamic accelerator technology for application to advanced hypersonic ground test (wind-tunnel) facilities. Both seeded and unseeded MHD accelerator concepts will be evaluated in the course of this program.

The unseeded MHD accelerator concept that MSE has proposed differs significantly from seeded MHD concepts that have been experimentally demonstrated in the past. Ionization is achieved and sustained by relying on a nonequilibrium process that uses an external energy source to initiate the ionization. Energy in the form of microwave, laser, or electron beams will be used as the ionization source in a region located immediately upstream of the MHD duct. Nonequilibrium ionization is sustained in the MHD channel by an imposed electric field. An external source may be used to supplement the effects of the electric field if necessary.

It is believed that MHD can overcome thermal and mechanical stress limitations by adding kinetic energy directly to the gas flow and by doing so provide a close simulation of actual hypersonic flight conditions.

MSE serves as the project manager for the National Aeronautics and Space Administration (NASA). Technical Service Contracts will be used for subcontractors with specific expertise in microwave, plasma, and MHD physics, and aerodynamic testing throughout the course of the project.

\section{Technology NeEdS}

Transatmospheric flight vehicles such as the $\mathrm{Na}$ tional Aerospace Plane (NASP) will be required to operate in hypersonic flight conditions that are different from those of subsonic, transonic, or supersonic flight vehicles, and testing of airframe and propulsion components in hypersonic flight regimes with full duplication of flight conditions is not possible in current ground test facilities. Testing of hypersonic components, especially air-breathing engines, requires actual flight conditions, including temperature, pressure, and air chemistry for flight Mach numbers as high as 16. As a result of inadequate ground test facilities, data for these flight regimes can currently only be obtained through costly flight tests.

No facilities currently exist that are capable of largescale propulsion testing above Mach 8. Air-breathing propulsion system development and propulsion/ airframe integration present the greatest challenges due to the need for high Mach numbers, true temperatures, and uncontaminated air environments. In this regime, there are a number of unanswered questions relating to boundary layers and chemical composition at engine inlets.

MHD technology overcomes these severe limitations by adding kinetic energy directly to the gas flow. Consequently, materials in the system are not exposed to such high stagnation temperatures and pressures.

To support such ground testing, facility requirements for duplicating flight conditions from Mach 8 to 16 have been recommended by various advisory 
sources [Science Advisory Board (SAB), Hypersonic Test Investment Program (HTIP), etc.]. A facility possessing this capability would ideally be able to support all required propulsion system, propulsion system/airframe integration, and aerothermal/structural testing. To accommodate a respectable size subscale total vehicle test, a test section of approximately 8 by 10 feet is required, with the capability for test section pressures and densities at least of an order of magnitude greater than flight values.

Based on technical reports and evaluations conducted by the SAB, the HTIP, and others, MHD technology appears to offer the best solution to U.S. ground test deficiencies. An MHD wind tunnel facility would provide the required capability for high Mach number testing of SCRAM jet engines as well as high-temperature materials and structures.

MHD augmentation of arc-heaters, shock tunnels, and other drivers can significantly extend hypersonic ground test capabilities. Analysis indicates that MHD can produce high-quality combustor inlet conditions for Mach numbers beyond 16 and perhaps beyond 20. Actual MHD tests conducted during the 1960 s by NASA and the U.S. Air Force produced very promising results and provided evidence that MHD is the one technology that can provide the ground testing capability required for testing hypersonic components for transatmospheric flight vehicles.

MHD also represents an excellent example of a dual-use technology. At the conclusion of the NASA- and U.S. Air Force-sponsored MHD accelerator research in the mid 1970s, DOE initiated a research and development program to develop MHD technology for use in coal-fired central power generation applications. This work concluded in 1993 with proof-of-concept testing successfully accomplished at both the DOE's WETO and the Coal Fired Flow Facility located in Tulahomma, Tennessee. Additionally, research of MHD technology for use in submarine propulsion systems, space-based pulse power systems, and nonlethal weapons systems has been conducted by both $\mathrm{DoD}$ and the Ballistic Missle Defense Organization (BMDO). These various applications have proven that MHD technology has tremendous potential to be successfully applied to both military and civilian applications on earth, in space, and on other extraterrestrial bodies.

\section{ACCOMPLISHMENTS}

- A Request for Proposal (RFP) has been issued to the University of Texas at Arlington to investigate testing alternatives for verifying the capability of MHD to function at high channel pressure.

- An RFP has been issued to Ohio State University for modification of plasma models to investigate nonequilibrium MHD performance and the effects of MHD on flow chemistry, including dissociation and molecular vibrational and rotational nonequilibrium.

- MSE has arranged meetings with Professor Vadim Alfyorov of the Central Aerohydrodynamic Institute (TsAGI) in Moscow, Russia, for the purpose of discussing a mutually beneficial cooperative program for the development of MHD accelerator technology. Professor Alfyorov visited MSE and presented seminars discussing his research, which includes researching and successfully operating seeded MHD accelerators at TsAGI for over 30 years. Although details of a cooperative program were not discussed, MSE and Professor Alfyorov agreed that such a program is of mutual interest and benefit.

- Discussions have been held with the following potential subcontractors and participants: University of Texas at Arlington; Ohio State University; ERC, Inc.; University of Tennessee Space Institure; Blue Sky Research; NASA Ames Research Center; Montana State University; Busek Inc.; TsAGI; University of Utah; and the INEL.

- Three technical papers have been published.

\section{Collaboration/TechNology}

\section{Transfer}

This project is being coordinated by DOE Pittsburgh Energy Technology Center (PETC) for NASA 
through MSE. Technical reviews are jointly held with the Radiatively-Driven Hypersonic Wind Tunnel project of the United States Air Force.

For further information, please contact:

Dr. Isaiah Blankson

Project Monitor

NASA HQ

(202) $358-4610$

John Wengle

U.S. Department of Energy

(301) $903-8490$

Allan Miller

Program Manager

MSE

(406) 494-7319 
ACRONYMS

Section 3.0 


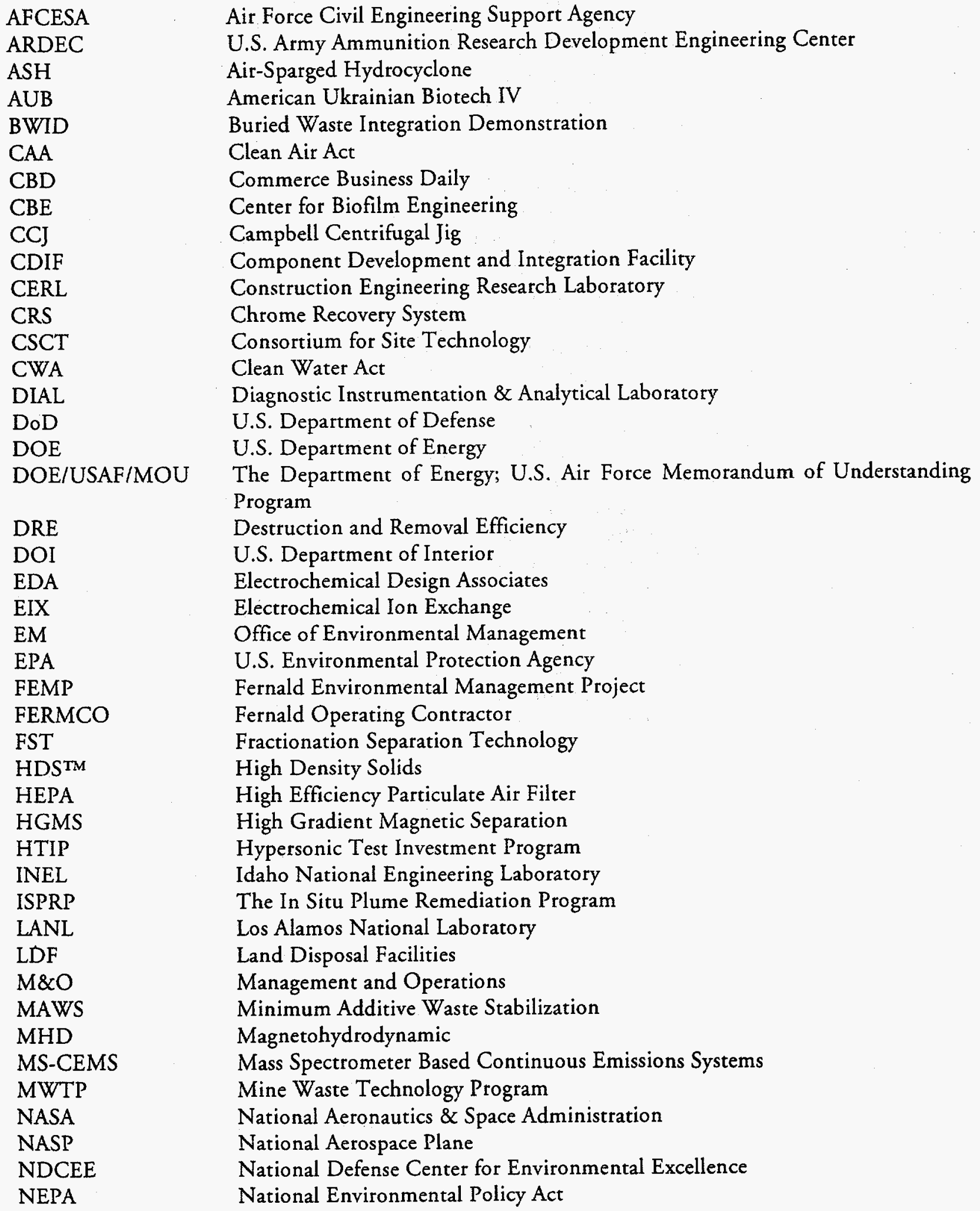




$\begin{array}{ll}\text { NTS } & \text { Nevada Test Site } \\ \text { ORNL } & \text { Oak Ridge National Laboratory } \\ \text { OST } & \text { Office of Science and Technology } \\ \text { PACT } & \text { Plasma Arc Centrifugal Treatment } \\ \text { PCAP } & \text { Pressure-Controled Atomization Process } \\ \text { PCT } & \text { Product Consistency Test } \\ \text { PES } & \text { Parsons Engineering Science } \\ \text { PETC } & \text { Pittsburgh Energy Technology Center } \\ \text { POP } & \text { Proof of Process } \\ \text { PPB } & \text { Parts per Billion } \\ \text { RCE } & \text { Rotating Cylinder Electrode } \\ \text { RCRA } & \text { Resource Conservation and Recovery Act } \\ \text { RDDT\&E } & \text { Research, Development, Demonstration, Testing, and Evaluation } \\ \text { RRP } & \text { Resource Recovery Project } \\ \text { RSM } & \text { Radioactive Scrap Metal } \\ \text { RSS } & \text { Radioactive Scrap Steels } \\ \text { RWMC } & \text { Radioactive Waste Management Complex } \\ \text { SAB } & \text { Science Advisory Board } \\ \text { SAIC } & \text { Science Application International Corporation } \\ \text { SCC } & \text { Secondary Combustion Chamber } \\ \text { SITE } & \text { Superfund Innovative Technology Evaluation } \\ \text { SNL } & \text { Sandia National Laboratories } \\ \text { SPE } & \text { Solid Phase Extraction } \\ \text { SSPF } & \text { Small-Scale Plasma Furnace } \\ \text { TCLP } & \text { Toxicity Characteristic Leaching Procedure } \\ \text { TTR } & \text { Tonopah Test Range } \\ \text { UMB } & \text { Ultramicrobacteria } \\ \text { UNR } & \text { University of Nevada in Reno } \\ \text { USNA } & \text { The United States Naval Academy } \\ \text { WETO } & \text { Western Environmental Technology Office } \\ \text { WVA } & \text { Watervliet Arsenal } \\ & \end{array}$

